\title{
PRELIMINARY RELIABILITY PREDICTION FOR THE FFTF CONCEPTUAL BUILDING ELECTRICAL POWER SYSTEM, SYSTEM 12
}

O. B. MONTEITH

AUGUST 1968

\section{AEC RESEARCH \& DEVELOPMENT REPORT}

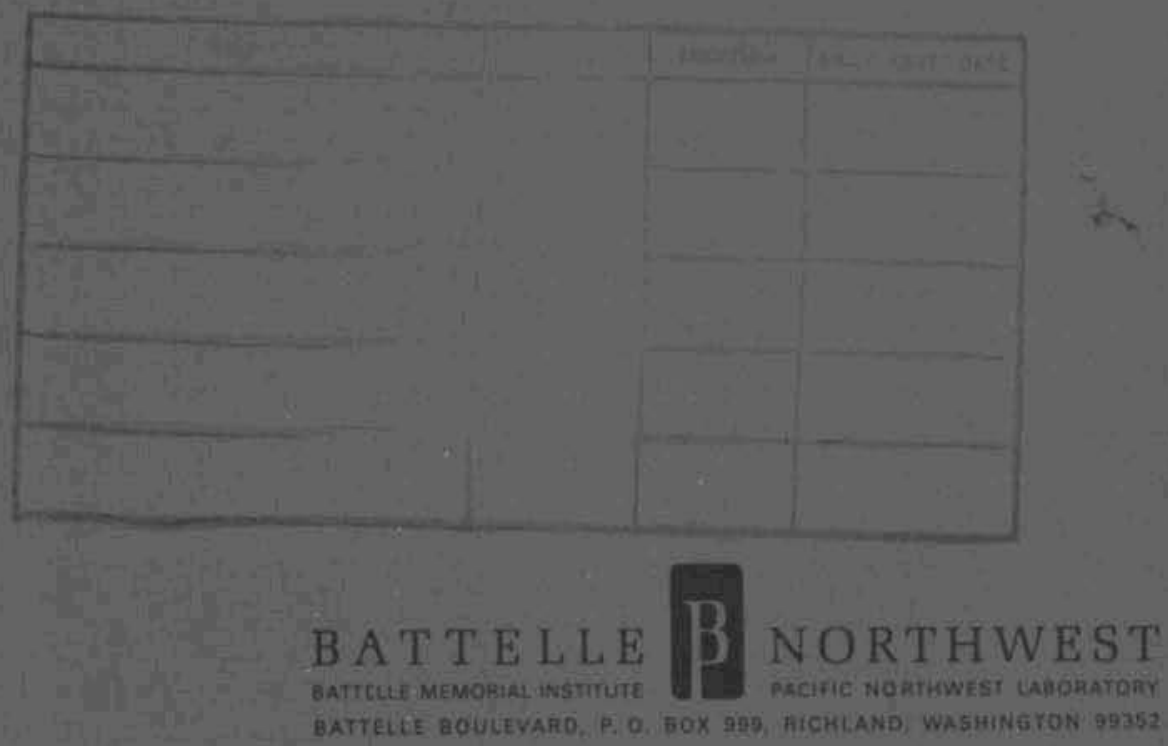




\section{LEGAL NOTICE}

This repart was prepared os on cccount of Government sponsored work: Neither the United Stotes, nor the Commissian, nor any person acting on beholf of the Commission:

A. Makes any warranty or representotion, expressed or implied, with respect to the accuracy, completaness, or usefulness of the information sentained in this report, or that the use af any information, opparatur, method, or process disciosed in this report moy not infringe privately awned rights; or

B. Assumes any liabilities with respect to the use of, or for damages resulting from the use of any informalion, opporatus, methed, or process disclosed in this report,

As used in the above, "person acting on behalf of the Commission" includes any employee or contractor of the Commission, or employee of such contractor, to the extent that such emplayee of con. tractor of the Commission, or employee of such controctor prepores, disseminates, or provides access to, any information pursuant to his employment or contract with the Commission, or his employment with such controctor.

\section{PACIFIC NORTHWEST LABORATORY}

NGHLAND, WASHINGTON

operated by

BATTELLE MEMORIAL INSTITUTE

for the

UNITED STATES ATOMIC ENERGY COMMISSION UNDER CONTRACT AT(45-1)-1830 
$\bullet$

33679000613531

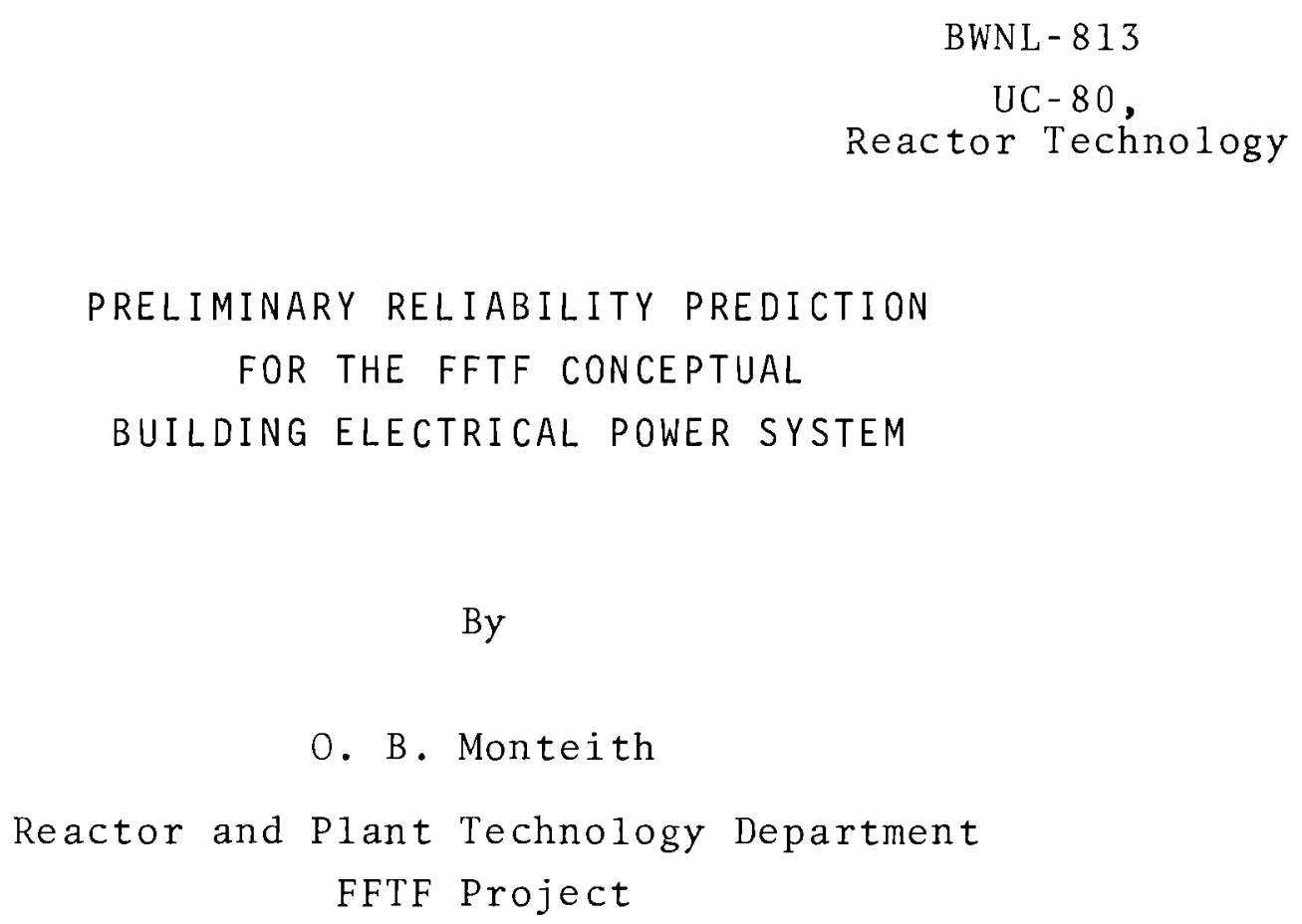

BWNL- 813

$\mathrm{UC}-80$

Reactor Technology

Froject

August 1968

BATTELLE MEMORIAL INSTITUTE

PACIFIC NORTHWEST LABORATORY

RI CHLAND, WASHINGTON 
Printed in the United States of America Available from

Clearinghouse for Federal Scientific and Technical Information National Bureau of Standards, U.S. Department of Commerce Springfield, Virginia 22151

Price: Printed Copy $\$ 3.00 ;$ Microfiche $\$ 0.65$ 


\section{TABLE OF CONTENTS}

LIST OF FIGURES .

INTRODUCTION

ASSUMPTIONS

SUMMARY AND CONCLUSIONS

SYSTEM OPERATIONAL REQUIREMENTS

System Functions and Boundaries. • • • • • • 6

Anticipated Operational Conditions. • • . • • 6

Mission Profiles and Duty Cycles • • • • • • 9

System Goals and Requirements . • • • . • • 9

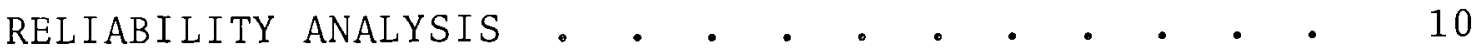

Analysis of the $2.4 \mathrm{kV}$ System,

Busses B5 through B9 • • • • • • • • • • 19

Analysis of the $480 \mathrm{~V}$ System,

Busses B13 through B20. • • • • • • • • • 23

Analysis of the Emergency Power Busses, B11 and B12 27

Analysis of the "Zero Time Outage" Busses . . . 33

Analysis of the $125 \mathrm{~V}$ DC and $24 \mathrm{~V}$ DC Busses. • 41

Analysis of the 120 Volt Alternate Current Busses. 48

Analysis of the Station Service. • • • • • • 50

Effects of Building Electrical Power

System Failures . . • . • • . . . 53

NOMENCLATURE • • • • • • • • • • • 。 • • 54

REFERENCES. • • • • • • • • • • • • • • 55 


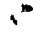

$\checkmark$

$\therefore$ 


\section{LIST OF FIGURES}

1 System 12 Functional Block Diagram

2 One Line Diagram of $13.8 \mathrm{kV}$ Feeders, $24 \mathrm{kV}$ and 480 Volt Switchgear

3 One Line Diagram of Instrument and Control and Direct Current Power Systems

4 One Line Diagram of 480 Volt Alternating Current Power System

$5 \quad$ Electrical Site Plan

6 One Line Diagram of: $2.4 \mathrm{kV}$ System 15

$7 \quad$ Example of Analysis Method 16

8 Reliability Block Diagram, $2.4 \mathrm{kV}$ System 20

$9 \quad$ Reliability Block Diagram, 480 Volt System 24

10 Reliability Block Diagram, Emergency Power Busses

11 Reliability Block Diagram, "Zero Time Outage" Busses

12 Re1iability Block Diagram, 125 Volt Direct Current System

13 Reliability Block Diagram, 120 Volt Instrument and Control Busses 49

14 Reliability Block Diagram for Station Service 
$\therefore$

$\checkmark$

$\therefore$

$r$ 


\author{
PRELIMINARY RELIABILITY PREDICTION \\ FOR THE FFTF CONCEPTUAL \\ BUILDING ELECTRICAL POWER SYSTEM, \\ SYSTEM 12 \\ Oscar B。 Monteith
}

INTRODUCTION

This report contains a preliminary reliability analysis of the FFTF Building Electrical Power System. Results of the analysis are preliminary because they are based on a conceptual design of the system (contained in the Conceptual System Design Description dated December 8, 1967) and on other systems of the FFTF which influence the design of the power system but are not yet fully defined. The purpose of this analysis is to obtain an early prediction of the Building Power System reliability and to explore analytical methods which can be used on a system of this complexity.

A suitable technique for predicting system reliability is not easily evolved. There are many equipment redundancies and alternative sources of power that are not amenable to conventional reliability analysis methods. In addition, each component can be repaired or replaced to restore the system in event of a failure.

The analytical method employed in this report is to combine elements in the reliability block diagram into progressively fewer and less complex arrangements, until a single logic block represents the assembly or a subsystem. The combinations are accomplished for series and parallel elements in the diagram. Complications arise because of the repairability of the components, and the conditional redundancies that exist. 
Each major bus of the Building Electrical System is analyzed and a prediction is made of the availability of power to the bus, the mean-time-between-failure of power to the bus, and the mean-time-to-restore the power in event of failure. Failure rates for the system components were obtained from references in most cases, and in others engineering estimates are employed. The repair times of the various components were established from operating experience, engineering estimates, and some literature data。 


\section{ASSUMPTIONS}

In the preparation of this analysis simplifying assumptions have been made; some of which are stated, others implied, A list of the more important assumptions follows :

1. The Building Electrical Power System is as described in the Conceptual System Description dated December, 1967.

2. Only single failures have been considered. Multiple failures, and dependent or secondary failures have not been included.

3. Components are operated in their useful life phase where the failure rate is constant and the distribution of the times between failures can be expressed by exponential distributions.

4. The distribution of repair times to restore the equipment from failed condition can be expressed by an exponential distribution.

5. Component failure rates and repair times have been estimated based on published data and engineering judgements 。

6. Repairs and testing do not alter the original design, nor add other faults.

7. The system and components perform exactly as designed and there are no design deficiencies.

8. The time required to switch a failed component from service and readjust loads is not included in the availability calculations. This switching will be effected at the control console and the time to respond will be minimal.

9. It is assumed that the operating policy will be to initiate reactor shutdown in event of loss of either normal source of power to the Emergency Power Busses. 


\section{SUMMARY AND CONCLUSIONS}

This reliability analysis predicts the availability, mean-time-between-failure, and the mean-time-to-restore electrical power to the various busses that make up the FFTF Building Electrical Power System.

A summary of the analysis results follows:

The $2.4 \mathrm{kV}$ system busses $5,6,7,8$, and 9 (4 out of 5 busses)

Availability of power $=0.999999785$

Mean-time-between-failure $=73,000,000 \mathrm{hr}$

Mean-time-to-restore $=15.6 \mathrm{hr}$

The $480 \mathrm{~V}$ system busses 13,14,15,16,17,18,19, and 20 (each bus)

Availability of power $=0.999999867$

Mean-time-between-failure $=130,000,000 \mathrm{hr}$

Mean-time-to-restore $=17.5 \mathrm{hr}$

The Emergency Power Busses 11 and 12 (each bus)

Availability of power $=0.999999999999565$

Me an-time-between-failure $=15,100,000,000,000 \mathrm{hr}$

Mean-time-to-restore $=6.6 \mathrm{hr}$

The $125 \mathrm{~V}$ dc busses (each of 3 busses)

Availability of power $=0.999999966$

Mean-time-between-failure $=54,000,000 \mathrm{hr}$

Mean-time-to-restore $=1.83 \mathrm{hr}$

The $24 \mathrm{~V}$ dc busses (each of 2 busses)

Availability of power $=0.999999983$

Mean-time-between-failure $=109,000,000 \mathrm{hr}$

Mean-time-to-restore $=1 \mathrm{hr}$

The "Zero Time Outage" Busses (each of 2 busses)

Availability of power $=0.9999999519$

Mean-time-between-failure $=106,000,000 \mathrm{hr}$

Mean-time-to-restore $=5.12 \mathrm{hr}$ 
The $120 \mathrm{~V}$ Instrument \& Control Busses (each of 2 busses)

Availability of power $=0.9999558$

Mean-time-between-failure $=100,000 \mathrm{hr}$

Mean $\propto$ time-to-restore $=4.4 \mathrm{hr}$

The Station Service dc Busses (each of 2 busses)

Availability of Power $=0.999999966$

Mean-time-between-failure $=55,000,000 \mathrm{hr}$

Mean-time-to-restore $=1.88 \mathrm{hr}$

The preliminary examination of System 12 analyzed here reveals no significant reliability shortcomings。

There are no suggestions to be gleaned from this analysis for changes in equipment configurations to improve reliability. Any improvements to be achieved would seem to be in the area of materials and methods of construction and these are beyond the scope of this document.

As a result of the planned operating procedure involving the emergency power busses, an expected unavailability of the FFTF as a result of failures in this equipment is predicted to be $0.76 \mathrm{hr}$ per $1000 \mathrm{hr}$ of operation. This is to be compared with the unavailability goal of $1 \mathrm{hr}$ per each 1000 hr of operation allocated to system 12 . 


\section{SYSTEM OPERATIONAL REQUIREMENTS}

\section{SYSTEM FUNCTIONS AND BOUNDARIES}

The Building Electrical Power System, System 12, provides equipment, circuits, and systems to receive the primary power, transform the voltage to the levels required by the various FFTF loads, and distribute the power via safe, protective and reliable circuitry. System 12 receives the primary power at $13.8 \mathrm{kV}$ and distributes it at $2400 \mathrm{~V}, 480 \mathrm{~V}$, and $120 \mathrm{~V}$ ac; and 125 and $24 \mathrm{~V}$ dc (see Figure 1). The distribution at al1 voltage levels is redundant in that no single insulation or equipment failure can cause the complete loss of a reactor function or major building service. Standby power, both ac and $\mathrm{dc}$, is provided in system 12 for emergency operation of the FFTF in event of failure of the normal power source.

System 12 receives power from the Primary Electrical Power System, System 11, and interfaces with nearly all other systems of the FFTF. In addition to providing power for process and service loads, it also supplies electrical heating for sodium piping and vessels. The electrical controls for some loads are included in system 12, in other cases the controls are included with the using FFTF system.

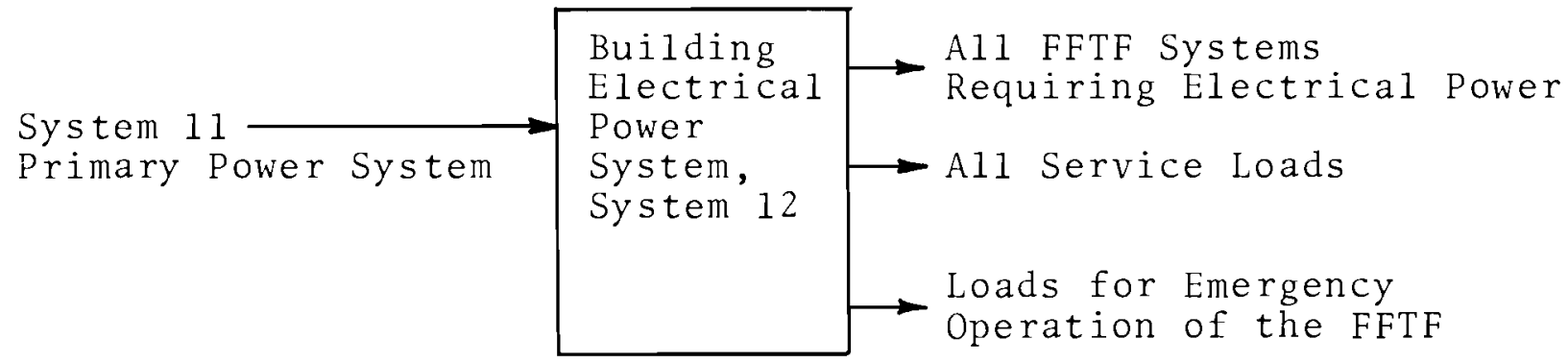

ANTICIPATED OPERATIONAL CONDITIONS

The Building Electrical Power System will use methods, components, and materials that have been proven reliable and safe in operation from long experience in industry. In some 


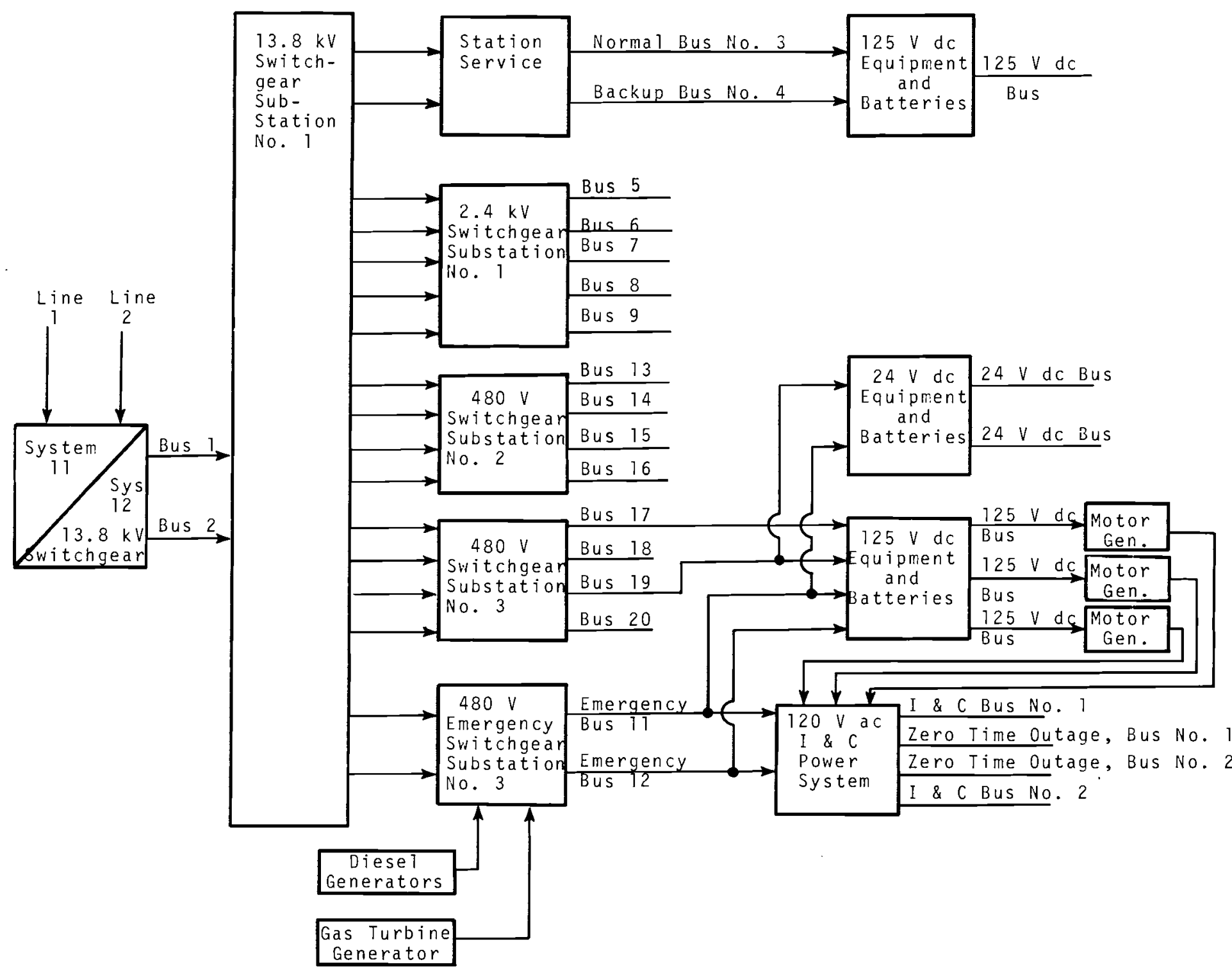

FIGURE 1. System 12 Functional Block Diagram 
cases electrical equipment will be subjected to environments of high temperature, high radiation, dry inert gases, or sodium vapors which are not encountered in the usual electrical application. In these cases, design study and development effort will be required to establish the required design. No problems are anticipated in providing these components.

Other operational considerations will enhance rather than detract from the system reliability. Thus, a basic design requirement is that "wiring and equipment shall be installed in such a manner as to prevent induced interference between separate systems that might result in erroneous signals。" Adequate switching will be provided for maintenance of major components without necessitating a total outage of any function or service. There is ample system capacity as a result of the designed $30 \%$ additional capacity for future growth, plus that which results from the diversity of the loads. Several other design requirements listed in the Conceptual System Design Description for System 12, wil1 aid in providing a reliable and operational design.

The anticipated interferences and interactions between System 12 and other FFTF systems are not new design problems, and the use of proven design techniques will reduce the adverse effects of electromagnetic interference, voltage surges and transients. The reliability analysis of system 11, (2) the Primary Electrical Power System, discusses the problem of lightning strokes and other surges which occur on the BPA System and which are conducted into System 12 via System 11 . Components of System 12 that are exposed to direct 1 ightning strokes will have adequate protection.

The operational plans for the emergency power bus present a need for special consideration. Present planning indicates that the standard operating procedure will be to initiate 
shutdown of the FTR in the event that the emergency power sources are activated. Thus, any failure in the two normal sources of power to the emergency busses will activate the emergency power supplies and cause reactor shutdown which results in reactor unavailability. The emergency power busses will need to be investigated for failures which can cause reactor unavailability.

MISSION PROFILES AND DUTY CYCLES

System 12 will be required to provide continuous power to the FFTF. The approximate duty cycle of the reactor is such that during each three month period three weeks are available during refueling which will permit shifting of loads for preventive maintenance. SYSTEM GOALS AND REQUIREMENTS

A requirement for the FFTF systems is that a failure in System 12 will not cause an unsafe condition at the reactor. In the actual conceptual system design a single failure of any equipment in system 12 will not result in a reactor unsafe condition. This is accomplished by the use of equipment and power source redundancies that are specified in the conceptual design.

A goal for System 12 has been established through the allocation of reactor unavailability to the various systems that make up the FFTF. Based on past experience with Hanford production reactors, an arbitrary goal for unavailability of the FFTF reactor, as a result of System 12 equipment failures, is established at less than $1 \mathrm{hr}$ per $1000 \mathrm{hr}$ of operation. 


\section{RELIABILITY ANALYSIS}

The building Electrical Power system is a combination of several subsystems with various interconnections. The conceptual design of System 12 is shown in Figures 2 through 6 of the Conceptual System Design Description.

It is the interconnections, combinations of the subsystems, and component repair capability which complicate the reliability analysis of the Building Electrical Power System。Thus, the $13.8 \mathrm{kV}$ system supplies the $2.4 \mathrm{kV}$ and $480 \mathrm{~V}$ systems; the $480 \mathrm{~V}$ system supplies the $120 \mathrm{~V}$ system, and $125 \mathrm{~V}$ dc and $24 \mathrm{~V}$ dc systems. An emergency power source is capable of supplying the emergency power bus in the event of the total loss of all normal power. Batteries will supply the dc busses in the event of total power failure. In addition, a number of equipment and subsystem redundancies are employed. All of the components are repair able either by replacement, or with/on-the-spot repairs in which the system restoration time varies from 1 to $168 \mathrm{hr}$ 。

Presented in this report is a reliability analysis for each of the busses that make up system 12. The results of the analysis yield the availability of electrical power to the bus, the mean-time-between-failure (MTBF) of power to the bus, and the mean-time-to-restore (MTTR) the power in event of failure.

The reliability analysis is developed from a reliability block diagram that represents the equipment supplying power to a bus. Each piece of equipment is represented in the diagram, and these blocks are then combined in accordance with the logical relations that establish the success of the path, or paths. The diagram is simplified by successive reductions until one block represents the assembly or subassembly. Some of these reductions are of series combinations, some are parallel combinations, and others follow from conditional probability arguments (Figure 7). 


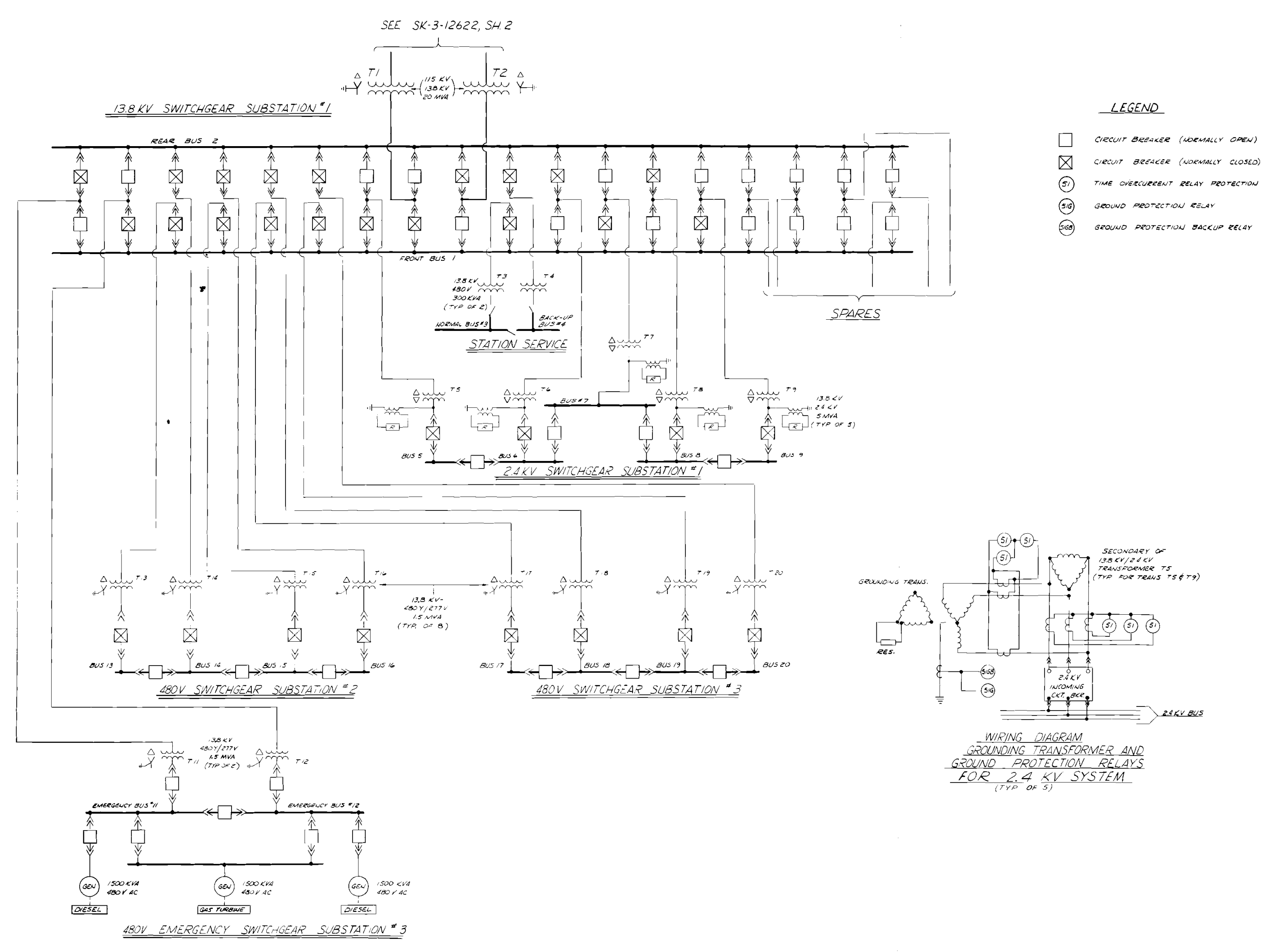




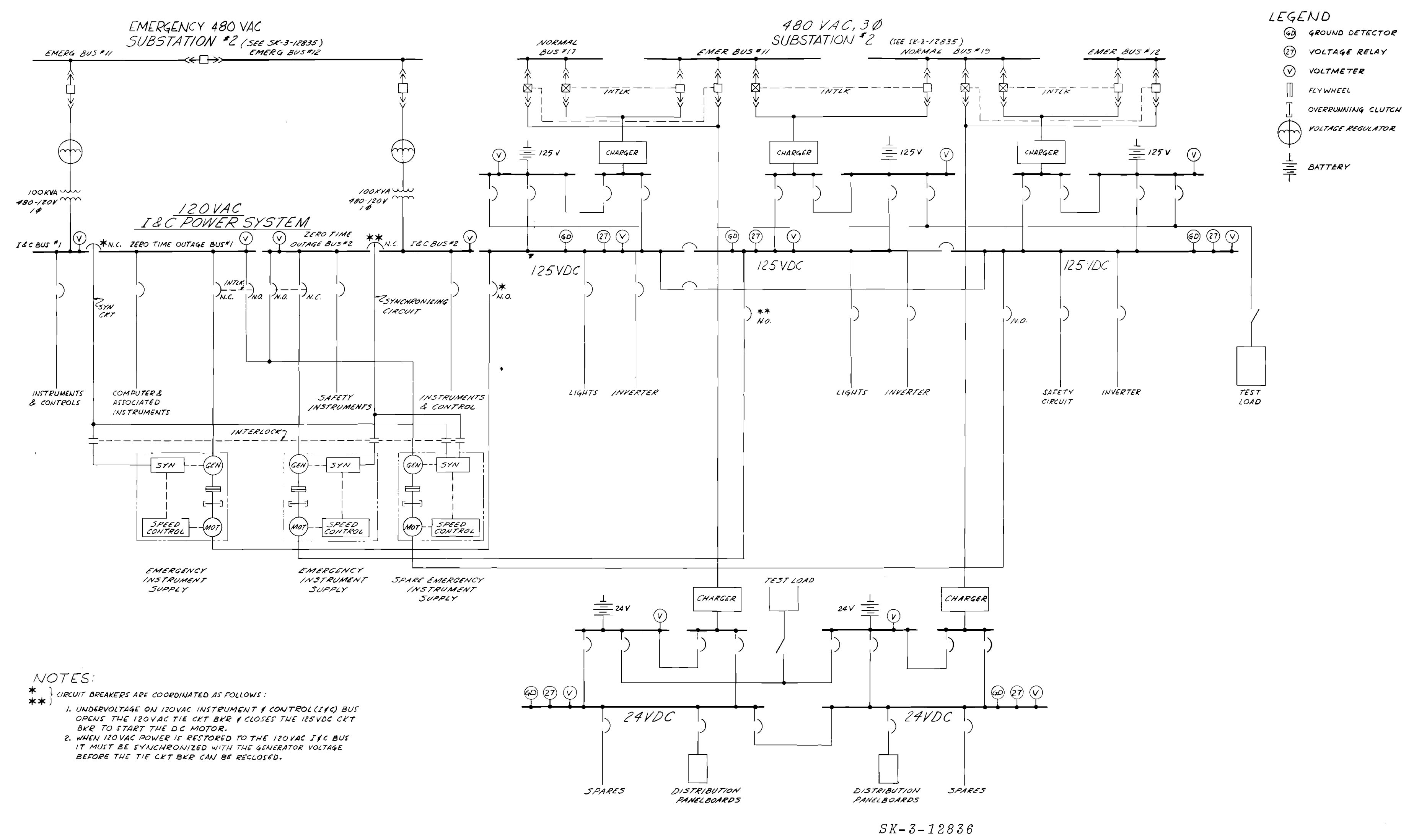

FIGURE 3. One Line Diagram of Instrument and Control, and Direct Current Power Systems 


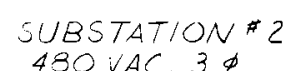

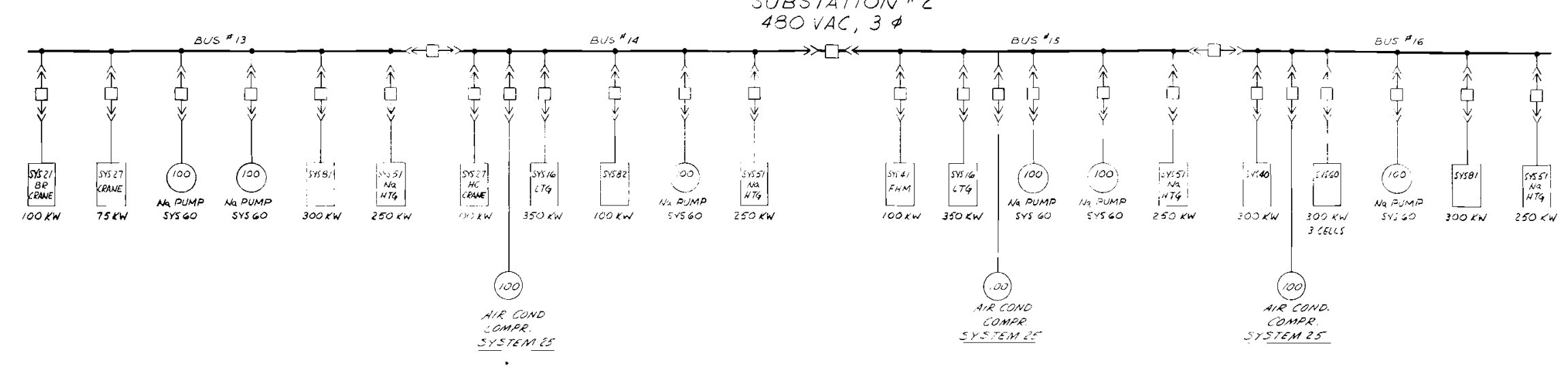

NOTES

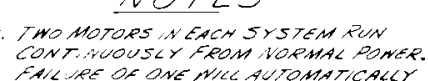

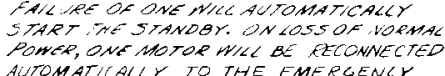

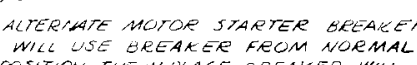

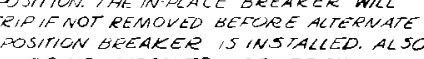

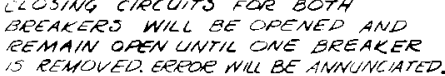

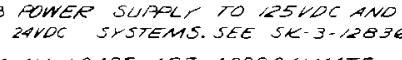

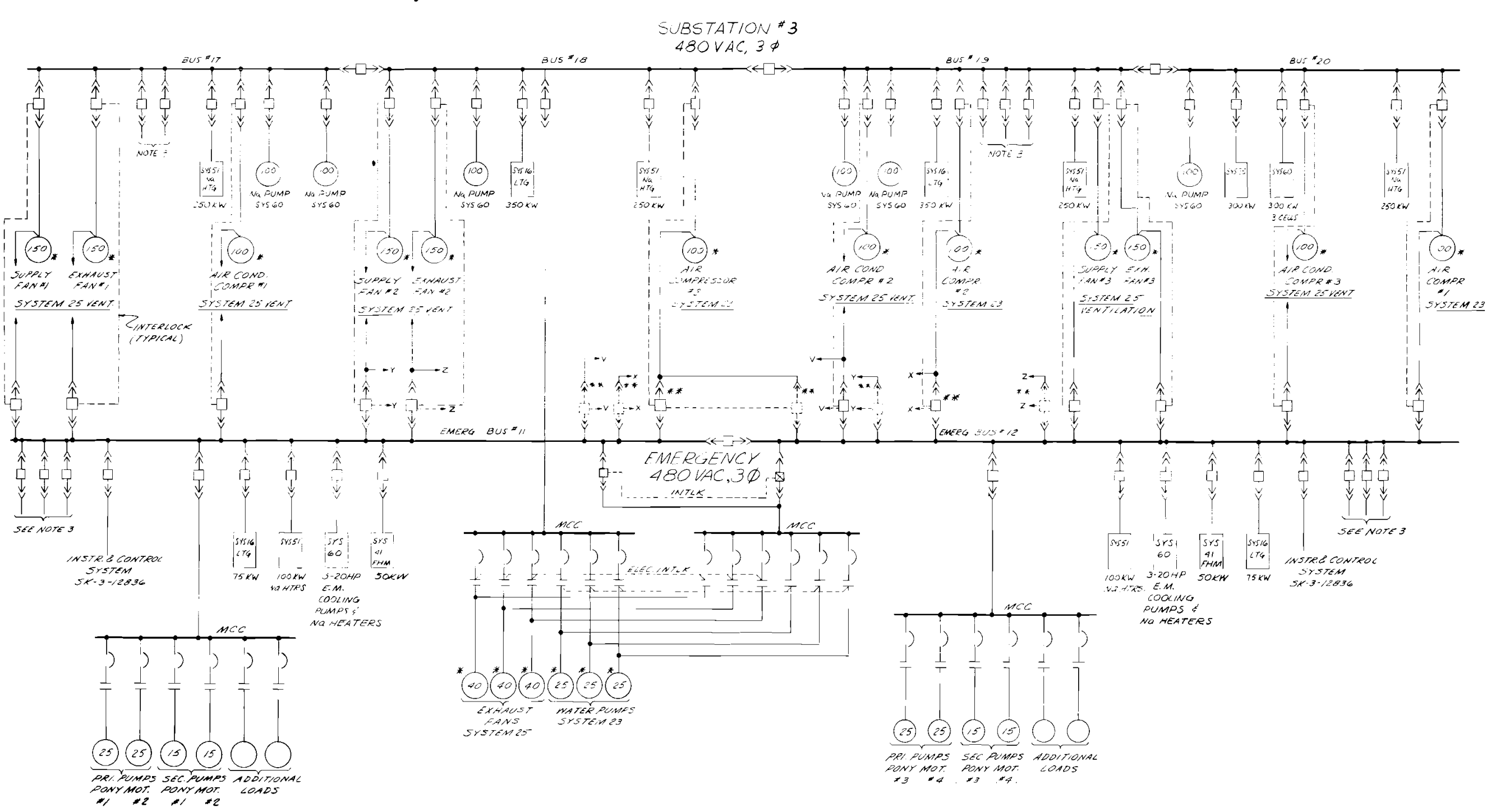

FIGURE 4. One Line Diagram of 480 Volt

$S K-3-12837$ Alternating Current Power System 


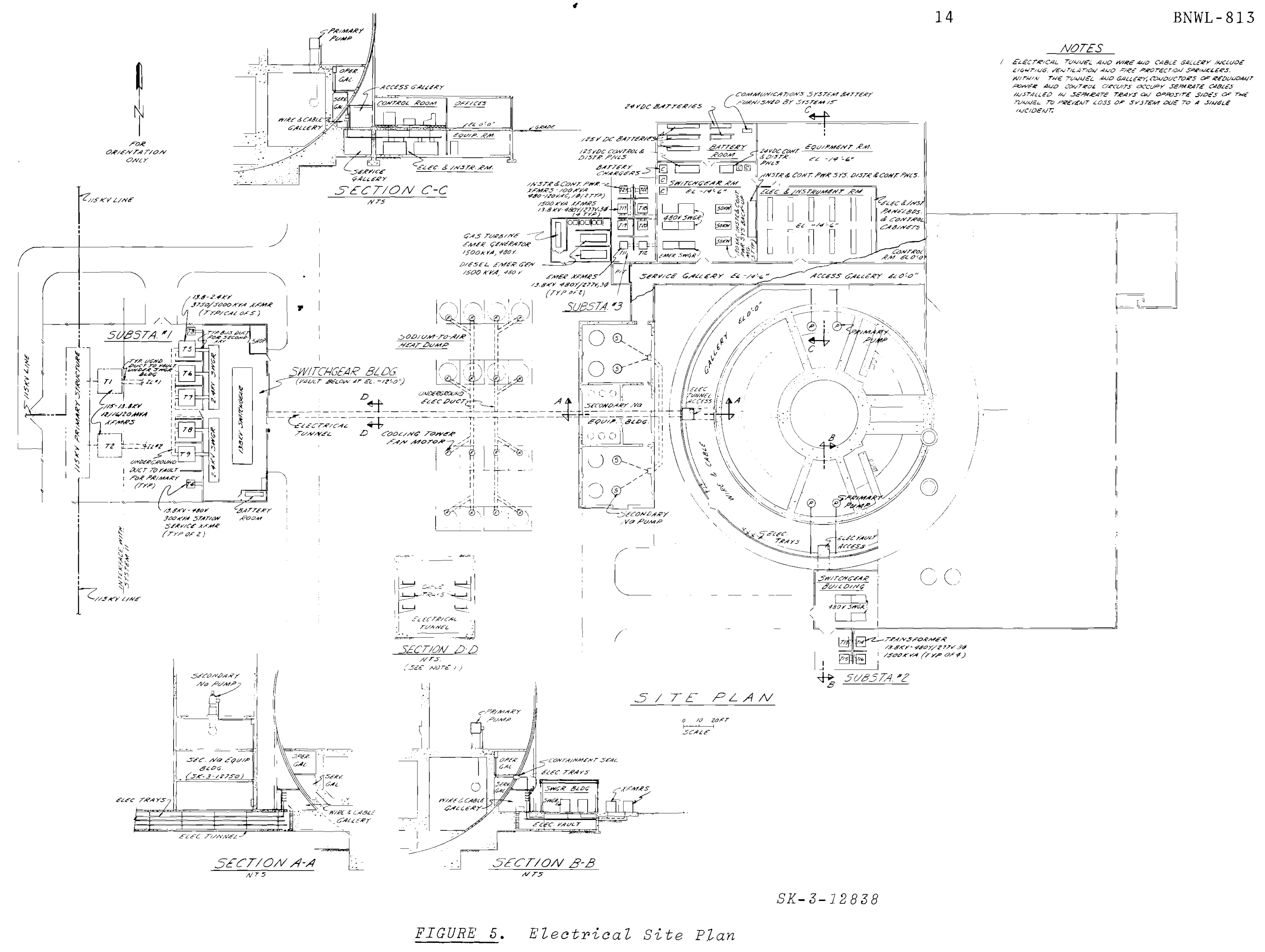



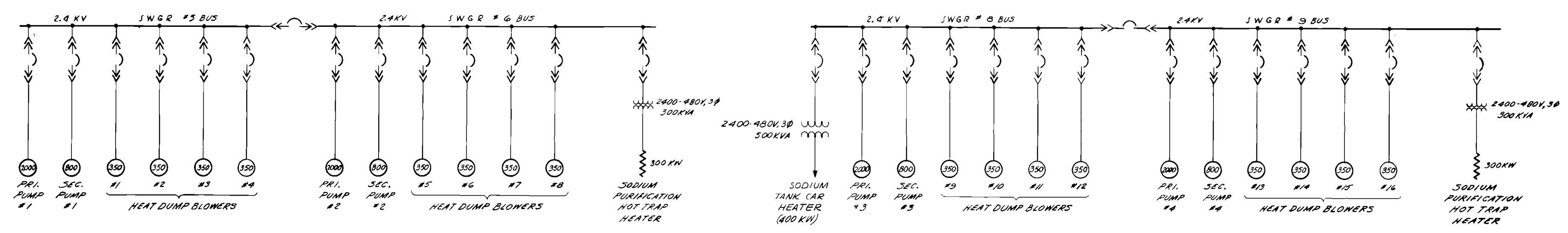

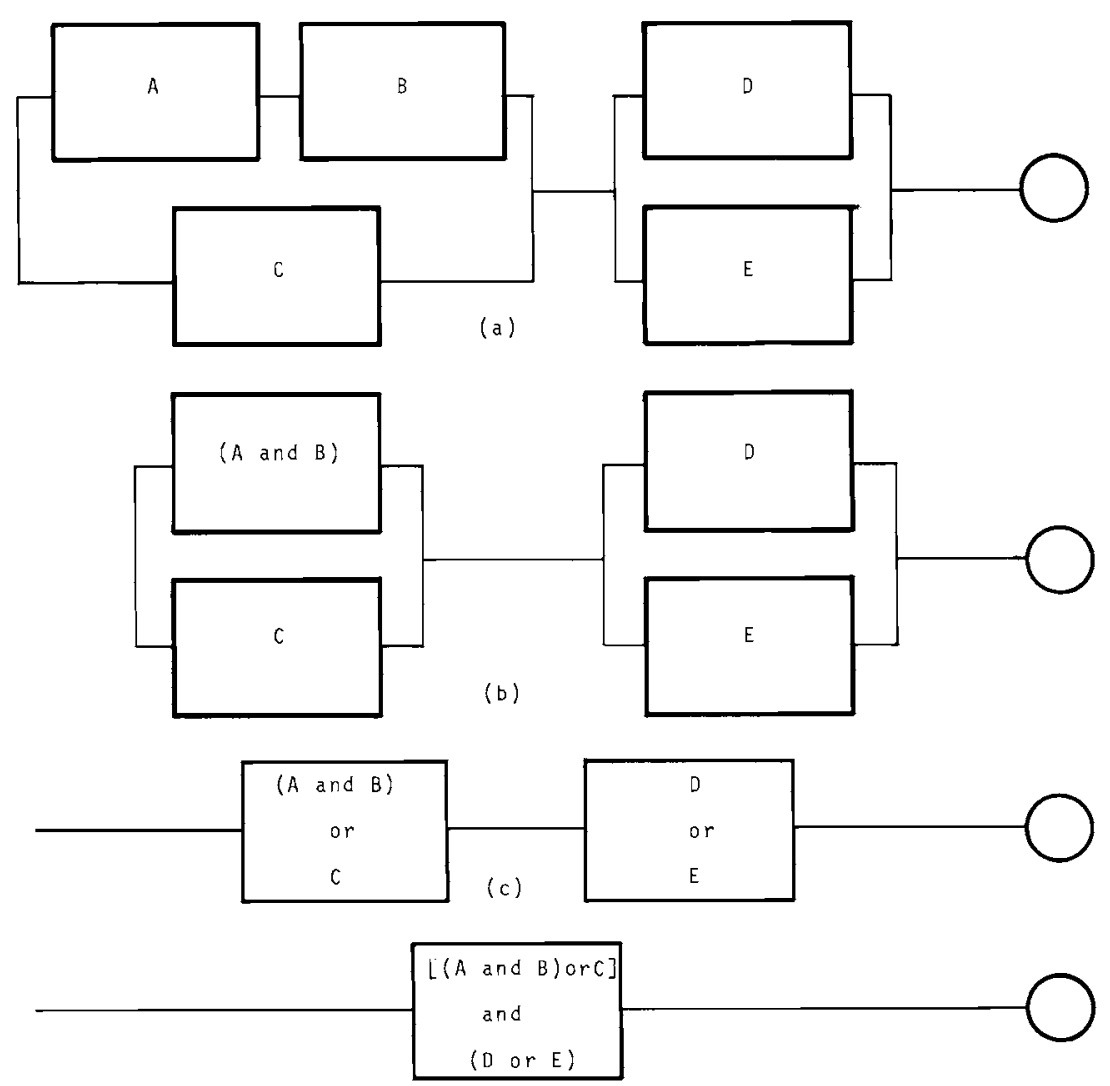

(d)

\section{FIGURE 7. Example of Analysis Method}

The analytical method employed in this report is to combine elements in the reliability block diagram into progressively fewer and less complex arrangements, until a single logic block represents the assembly or subsystem. This technique is outlined in Chapters 7 and 8 of Reliability - Engineering, (3) by the Staff of ARINC Research Corporation, edited by W. H. Von Alven. An example follows. Part (a) is the system and Part (b) is the first reduction wherein the series elements $A$ and $B$ are combined. The two paralle 1 combinations of (b) are then combined to give two series elements in (c). The final combination of the two series elements in (c) gives the single block (d) which represents the system. 
Table I is a list of the equipment failure rates and the time to restore for the components that make up system 12 . Included in the list is the reference from which the various values were obtained.

In addition to availability, MTBF, and MTTR power to the busses; a calculation is made to determine the same numerical values for power to any connected load. It is significant to note that availability and MTBF of power to any load is lower than for the bus, because the equipment connecting the load to the bus is a series logic path which becomes the dominant factor in the values.

In each of the reliability diagrams a block is included which represents the logical position in the diagram for System 11 which is the Primary Electrical Power System. The values of availability, MTBF, and MTTR for system 11 are not included in this analysis of system 12 since the concern here is to evaluate the system 12 equipment. This has been done by assuming the block for system 11 is a perfect component without failure. 
TABLE I. Equipment Failure Rates and Time to Restore

\begin{tabular}{|c|c|c|c|c|}
\hline & $\begin{array}{l}\text { Failures Per } \\
\text { Million Hours }\end{array}$ & Reference & $\begin{array}{c}\text { Time to Restore, } \\
\mathrm{hr} \\
\end{array}$ & Reference \\
\hline $13.8 \mathrm{kV}$ Circuit Breaker & 0.65 & 4 & 1 & $4, *$ \\
\hline $13.8 \mathrm{kV} \mathrm{Cable}$ & $3.8 / 1000 \mathrm{ft}$ & 4 & 48 & $4, *$ \\
\hline $13.8 \mathrm{kV}$ Bus & 1.8 & 5 & 8 & * \\
\hline $13.8 / 2.4 \mathrm{kV}$ Transformer & 0.60 & 4 & 168 & * \\
\hline $2.4 \mathrm{kV}$ Circuit Breaker & 0.65 & 4 & 1 & * \\
\hline $2.4 \mathrm{kV} \mathrm{Cable}$ & $3.8 / 1000 \mathrm{ft}$ & 4 & 48 & $4, *$ \\
\hline $2.4 \mathrm{kV}$ Bus & 1.8 & 5 & 8 & * \\
\hline $13.8 / .480 \mathrm{kV}$ Transformer & 0.94 & 4 & 168 & * \\
\hline $600 \mathrm{~V} \mathrm{Cab} 1 \mathrm{e}$ & $2.7 / 1000 \mathrm{ft}$ & 4 & 48 & $4, *$ \\
\hline $480 \mathrm{~V}$ Circuit Breaker & 2.3 & 4 & 1 & * \\
\hline $480 / 120 \mathrm{~V}$ Transformer & 0.94 & 4 & 8 & * \\
\hline $480 \mathrm{~V}$ Bus & 1.8 & 5 & 8 & * \\
\hline Cable Joints \& Terminations & 0.24 & 4 & 24 & $4, *$ \\
\hline $\begin{array}{ll} & \text { Start }=0.998 \\
\text { Diese1 } & \text { Run }\end{array}$ & 59 & $6,7,8$ & $\begin{array}{l}5 \\
5\end{array}$ & $6,7,8$ \\
\hline $\begin{array}{ll}\text { Turbine } & \text { Start }=0.999 \\
\text { Run }\end{array}$ & 100 & $6,7,8$ & $\begin{array}{l}4 \\
4\end{array}$ & $6,7,8$ \\
\hline $1500 \mathrm{kVA} 480 \mathrm{~V}$ Generator & 10 & $4, *$ & 168 & * \\
\hline $480 \mathrm{~V}$ Voltage Regulator & 5 & * & 4 & * \\
\hline $120 \mathrm{~V}$ Circuit Breaker & 2.5 & * & 1 & * \\
\hline $125 \mathrm{~V}$ dc Power Supply & 20 & * & 4 & $*$ \\
\hline $125 \mathrm{~V}$ dc Battery & 100 & * & 4 & * \\
\hline $75 \mathrm{HP} 125 \mathrm{~V}$ dc Motor & 5 & $4, *$ & 80 & $4, *$ \\
\hline 60 kVA Synchronous Motor & 5.9 & $4, *$ & 78 & $4, *$ \\
\hline C1utch & 3.0 & 8 & 4 & * \\
\hline $24 \mathrm{~V}$ dc Power Supp1y & 20 & * & 4 & * \\
\hline $24 \mathrm{~V}$ dc Battery & 50 & * & 4 & * \\
\hline $24 \mathrm{~V}$ dc dc Circuit Breaker & 2.0 & $*$ & 1 & * \\
\hline $125 \mathrm{~V}$ dc dc Circuit Breaker & 2.0 & * & 1 & * \\
\hline
\end{tabular}

* Estimate based on Hanford Experience and engineering judgment 
ANALYSIS OF THE $2.4 \mathrm{kV}$ SYSTEM, BUSSES B5 THROUGH B9

The $2.4 \mathrm{kV}$ system is made up of five busses, each supplied from the $13.8 \mathrm{kV}$ system through a circuit breaker, cable, and $13.8 \mathrm{kV} / 2.4 \mathrm{kV}, 5 \mathrm{MVA}$ transformer。 Its major load is the FFTF Heat Transport System, System 50。 The $2.4 \mathrm{kV}$ system supplies four primary coolant loop pump motors, four secondary coolant loop pump motors, 16 heat dump blower motors, and three sodium heating loads. These loads are connected to four of the five busses, with the fifth bus energized but supplying no load. In event of power loss to any one of the four loaded busses, the fifth bus can be switched to pick up the load of the power deficient bus.

This arrangement of busses and loading constitutes a form of redundancy. However, in the reliability context it is not pure operational redundancy, and it is not pure standby redundancy。 For this analysis the combination described above is being considered as a four out of five operational redundancy with the knowledge that this is an approximation, and that the error is small.

The reliability block diagram of the $2.4 \mathrm{kV}$ system is shown in Figure 8 and the results of the analysis are as follows :

$$
\begin{aligned}
& \text { For four out of five } 2.4 \mathrm{kV} \text { busses } \\
& \begin{array}{l}
\text { Availability of power }=0.999999785 \\
\text { (unavailability }=0.215 \times 10^{-6} \text { ) } \\
\text { Mean-time-between-failure }=73,000,000 \mathrm{hr} \\
\text { Mean-time-to-restore }=15.6 \mathrm{hr} \\
\text { For any 2.4 } \mathrm{kV} \text { load } \\
\text { Availability of power }=0.999878 \\
\text { (unavailability }=122 \times 10^{-6} \text { ) } \\
\text { Mean-time-between-failure }=290,000 \mathrm{hr} \\
\text { Mean-time-to-restore }=35.5 \mathrm{hr}
\end{array}
\end{aligned}
$$




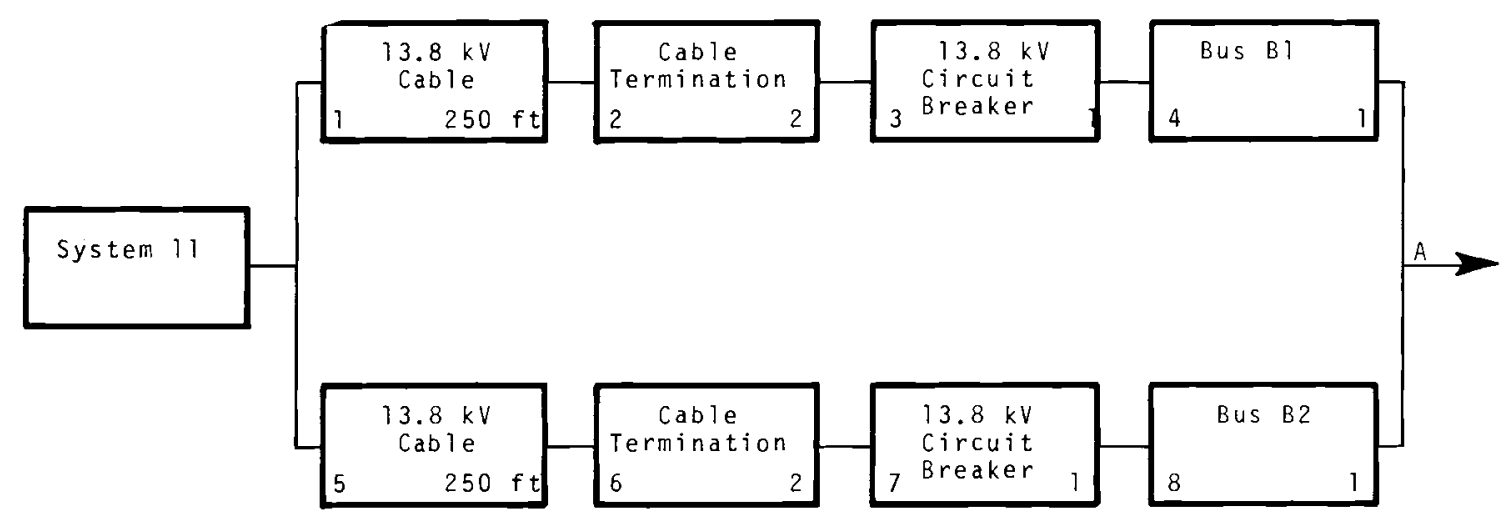




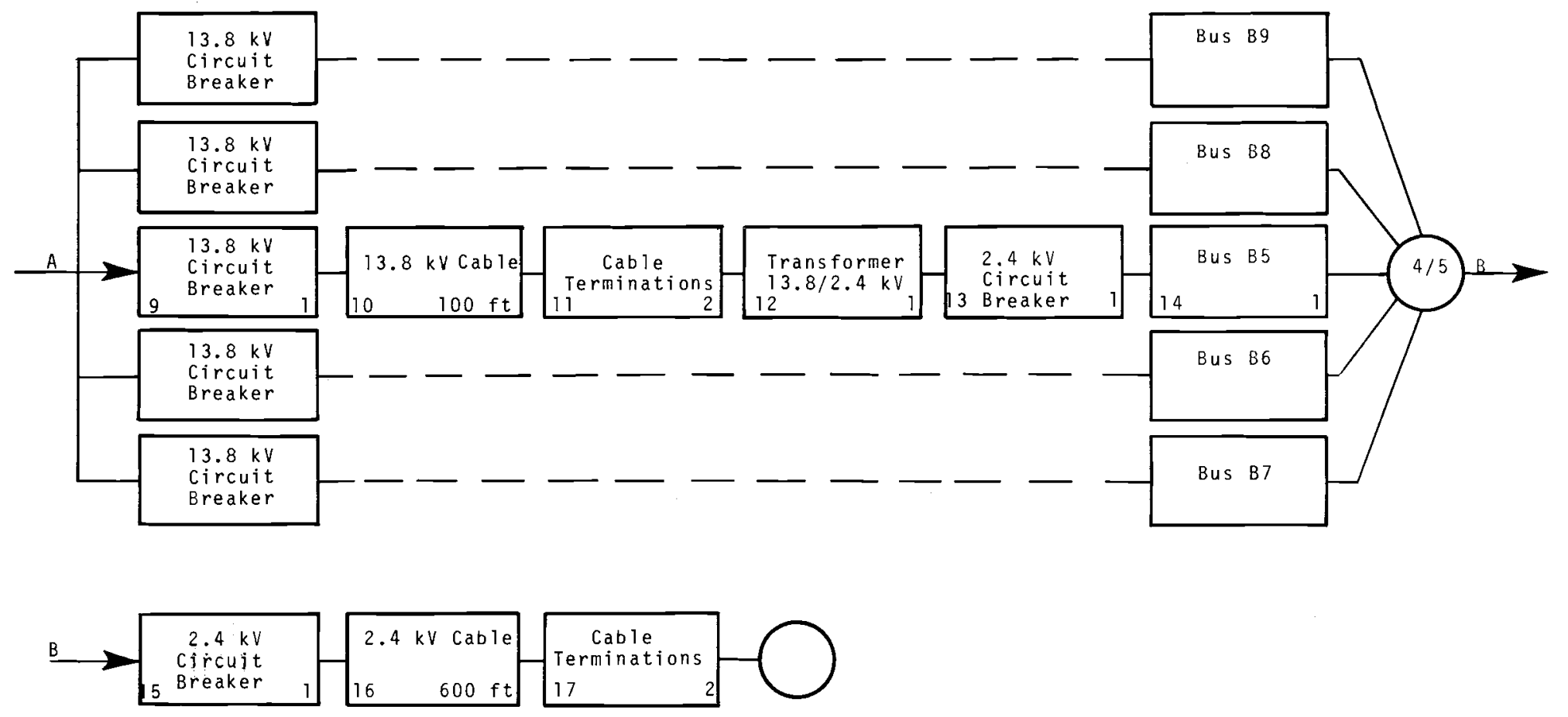




$$
\begin{aligned}
& \mathrm{A}_{2.4 \mathrm{kV}}=\left([ 1 - ( \lambda _ { 1 } { } ^ { \tau } 1 + \lambda _ { 2 } { } ^ { \tau } 2 + \lambda _ { 3 } { } ^ { \tau } 3 + \lambda _ { 4 } { } ^ { \tau } 4 ) ^ { 2 } ] \left\{5 \left[1-\left(\lambda_{9}{ }^{\tau} 9+\lambda_{10}{ }^{\tau} 10+\lambda_{11}{ }^{\tau} 11\right.\right.\right.\right. \\
& \left.\left.+\lambda_{12}{ }^{\tau} 12+\lambda_{13^{\top} 13}+\lambda_{14}{ }^{\tau} 14\right)\right]^{4} \\
& \left.-4\left[1-\left(\lambda_{9}{ }^{\tau} 9+\lambda_{10^{\tau} 10}+\lambda_{11^{\tau} 11}+\lambda_{12^{\tau} 12}+\lambda_{13^{\tau} 13}+\lambda_{14}{ }^{\tau} 14\right)\right]^{5}\right\} \\
& \frac{1}{()_{2.4 \mathrm{kV}}}=\left(\lambda_{1}{ }^{\tau} 1+\lambda_{2}{ }_{2}+\lambda_{3}{ }_{3}+\lambda_{4} \tau_{4}\right)\left[2\left(\lambda_{1}+\lambda_{2}+\lambda_{3}+\lambda_{4}\right)\right] \\
& {\left[1-\left(\lambda_{1} \tau_{1}+\lambda_{2} \tau_{2}+\lambda_{3} \tau_{3}+\lambda_{4} \tau_{4}\right)\right]} \\
& +20\left\{\left[1-\left(\lambda_{9}{ }^{\top} 9+\lambda_{10}{ }^{\tau} 10+\lambda_{11}{ }^{\tau} 11+\lambda_{12}{ }^{\tau} 12+\lambda_{13}{ }^{\tau} 13+\lambda_{14}{ }^{\tau} 14\right)\right]^{3}\right.
\end{aligned}
$$

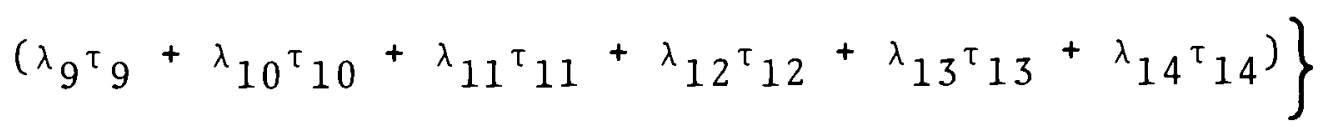

$$
\begin{aligned}
& \left\{\lambda_{9}+\lambda_{10}+\lambda_{11}+\lambda_{12}+\lambda_{13}+\lambda_{14}\right\} \\
& \tau_{2.4 \mathrm{kV}}=\frac{\left(1-\mathrm{A}_{2.4 \mathrm{kV}}\right) \bigodot_{2.4 \mathrm{kV}}}{\mathrm{A}_{2.4 \mathrm{kV}}}
\end{aligned}
$$


ANALYSIS OF THE $480 \mathrm{~V}$ SYSTEM, BUSSES B13 THROUGH B20

The normal 480 volt system comprises eight busses each supplied from the $13.8 \mathrm{kV}$ system through a circuit breaker, cable, and $13.8 \mathrm{kV} / 480 \mathrm{~V}, 1.5$ MVA transformer. After providing for the loads of the heat transport system, System 12 supplies the remaining FFTF electrical loads by the $480 \mathrm{~V}$ system as a normal source. The conceptual design of these busses includes approximately $40 \%$ overcapacity for the anticipated requirements. In addition, there is a diversity of loads which yields further available capacity. The planned operation of the $480 \mathrm{~V}$ system provides for switching of the loads from a failed bus to an adjacent bus, through bus-tie breakers. In the event that switching is required, some noncritical loads may be disconnected to carry both loads adequately on one bus.

The conditions of operation and bus arrangement noted above are representative of operational redundancy. Though the $480 \mathrm{~V}$ system does not meet all the requirements for operational redundancy, it is a satisfactory approach for this analysis. A rigorous analysis would be more complicated and time consuming than the results would warrant。

The reliability block diagram of one $480 \mathrm{~V}$ bus is shown in Figure 9. A11 of the busses, B13 through B20 are considered to be identical. The results of the analysis are as follows:

For one $480 \mathrm{~V}$ bus

Availability of power $=0.999999867$ (unavailability $=0.133 \times 10^{-6}$ )

Mean-time-between-failure $=130,000,000 \mathrm{hr}$

Mean-time-to-restore $=17.5 \mathrm{hr}$

For any $480 \mathrm{~V}$ load

Availability of power $=0.9999182$ (unavailability $=81.8 \times 10^{-6}$ )

Mean-time-between-failure $=183,000 \mathrm{hr}$

Mean-time-to-restore $=15 \mathrm{hr}$ 


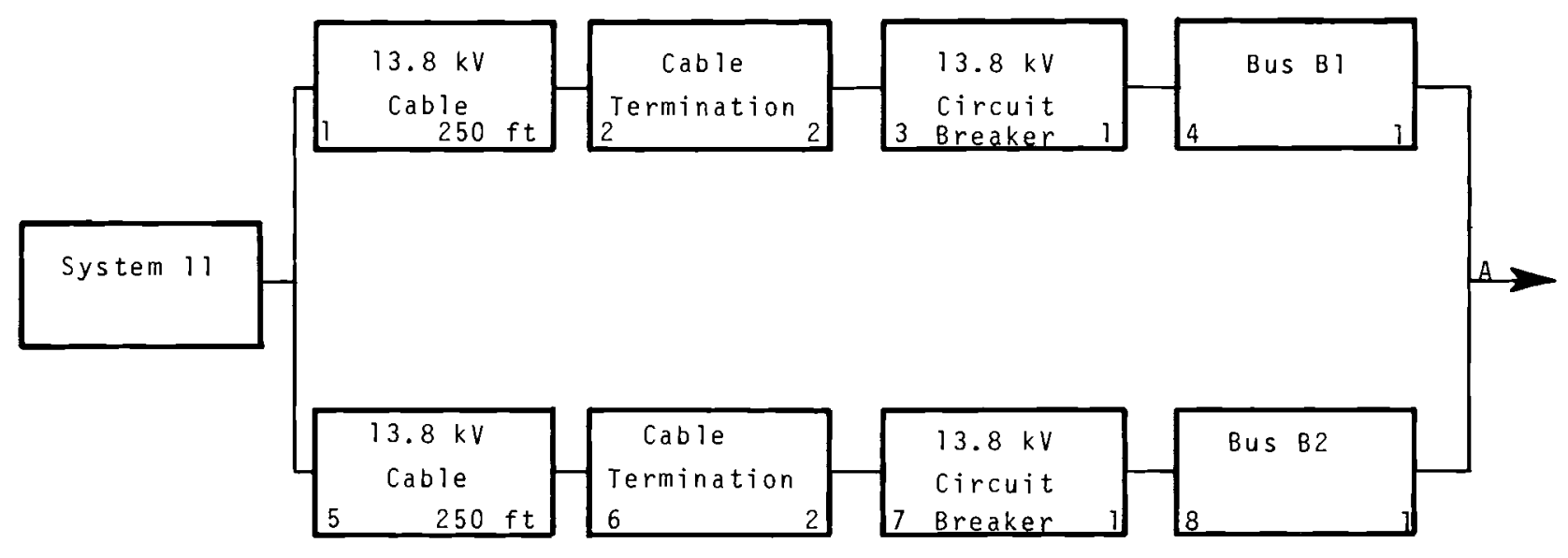




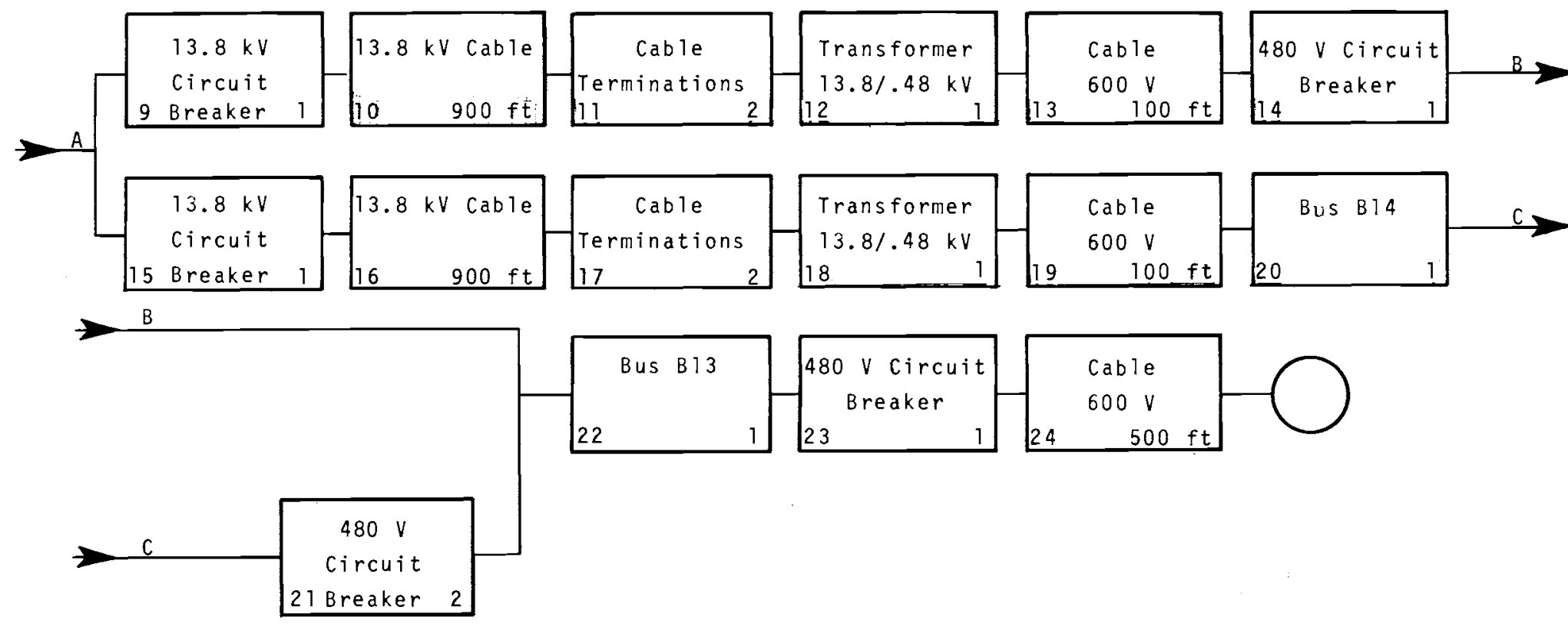

FIGURE 9. (Contd) 


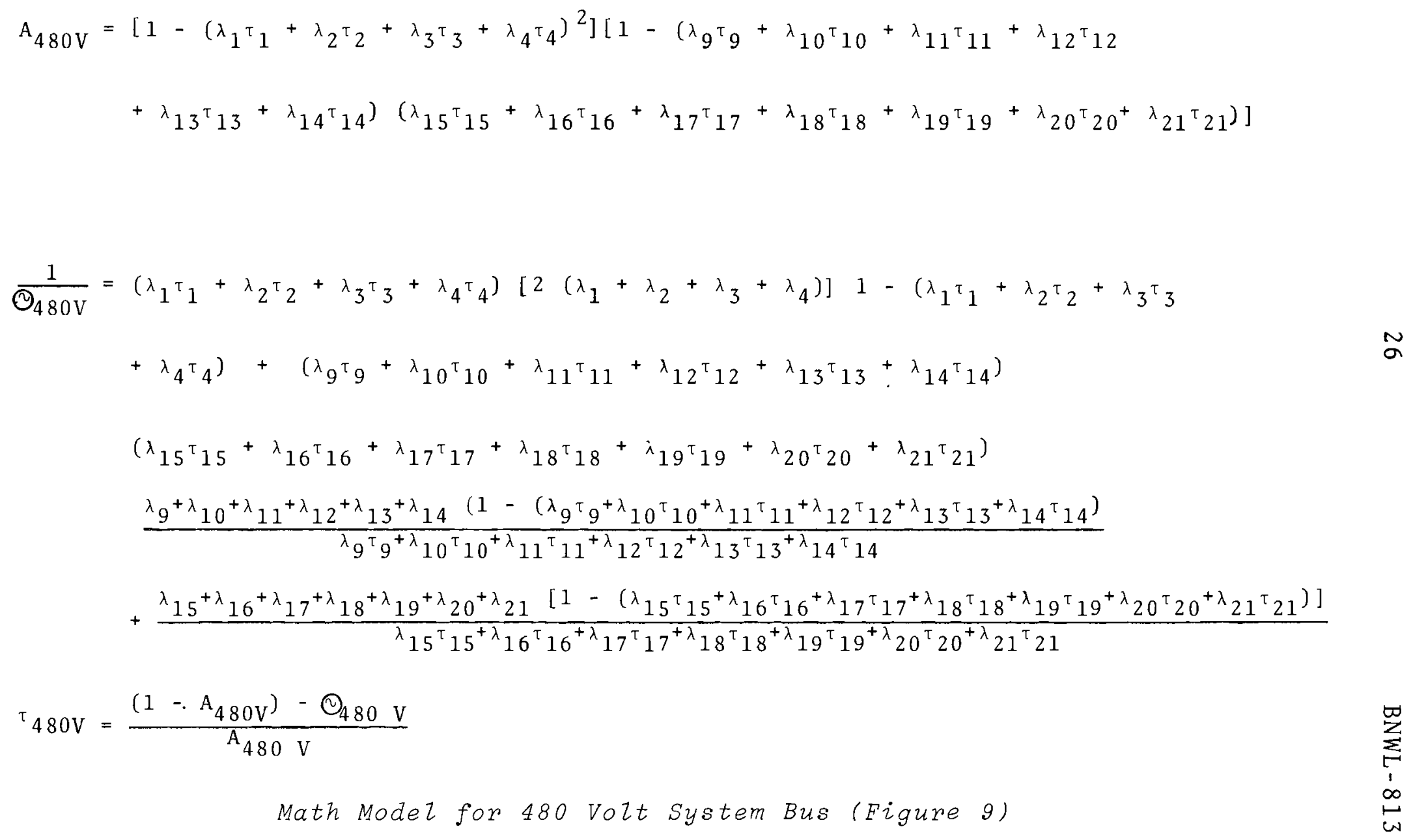




\section{ANALYSIS OF THE EMERGENCY POWER BUSSES, B 11 AND B 12}

The emergency power busses supply critical reactor auxiliaries and building service loads which include the pony motors for the primary and secondary sodium pumps, selected ventilation equipment, instrument and control systems, and others that are listed in the CSDD for System 12. There are two separate sources of power for the emergency busses; (a) normal power is provided from the $13.8 \mathrm{kV}$ system by redundant paths of circuit breaker, cable, and $13.8 \mathrm{kV} / 480 \mathrm{~V}$, 1.5 MVA transformer, and (b) emergency power from a redundant combination of a 1500 kVA diesel driven generator and a $1500 \mathrm{kVA}$ gas turbine driven generator.

This analysis is based on the failure of either path of the normal primary power, and therefore the turbine unit is considered a redundant source for the diesel unit connected to the failed bus.

The switchover from normal power to emergency power is automatically actuated by loss of normal power. There is approximately 5 to $20 \mathrm{sec}$ delay in restoring power in the event of switchover as this period is required to start the diese 1 and gas turbine drives and bring them up to speed.

A complication to the reliability analysis of this equipment combination is the standby mode of the diesel and gas turbine drives, and their expected starting unreliability。 To facilitate the analysis, a starting reliability was determined for the diesel and turbine based on successes in a number of starts, and the expected number of starts to be required of this equipment in the FFTF. The combination of diesel and turbine driven generators are then considered as redundant equipment. This reliability model is an approximation and the error involved is not easily determined. 
The reliability block diagram of the emergency power busses, B11 and B12 is shown in Figure 10. The two busses are considered to be identical for this analysis. The results of the analysis are as follows:

For the emergency bus

Availability of power $=0.999999999999565$ (unavailability $=4.35 \times 10^{-13}$ )

Mean-time-between-failure $=15,100,000,000,000 \mathrm{hr}$ Mean-time-to-restore $=6.6 \mathrm{hr}$

For any load on the emergency bus

Availability of power $=0.9999833$

(unavailability $=16.7 \times 10^{-6}$ )

Mean-time-between-failure $=244,000 \mathrm{hr}$

Mean-time-to-restore $=4.1 \mathrm{hr}$

The planned operation of the emergency system will be to start both diesels and the turbine drives in the event of a failure in either of the normal primary power sources. The turbine drive will then act as a redundant source to whichever diesel is required to supply the emergency bus. The second diesel will be started as a precaution. The analysis presented above does not consider the case of both normal primary sources failing since this is a multiple failure. However, the capacity of the emergency generators is such that any one of the three generator sources can supply the total emergency shutdown load. An approximation to establish the availability of a one-out-of-three combination of the three emergency generator sources yields the following:

$$
\begin{array}{cl}
A=0.999999992 & \text { for one out of three emergency } \\
& \text { generator sources }
\end{array}
$$

This is the availability of power from the generators alone, without considering power from the normal primary sources. 


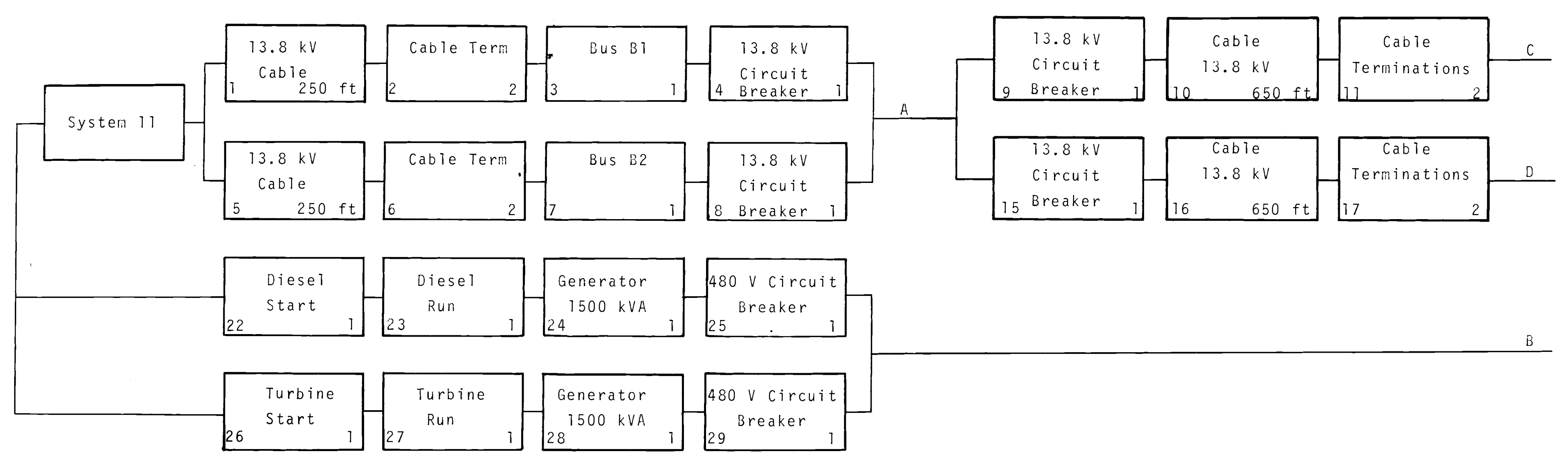




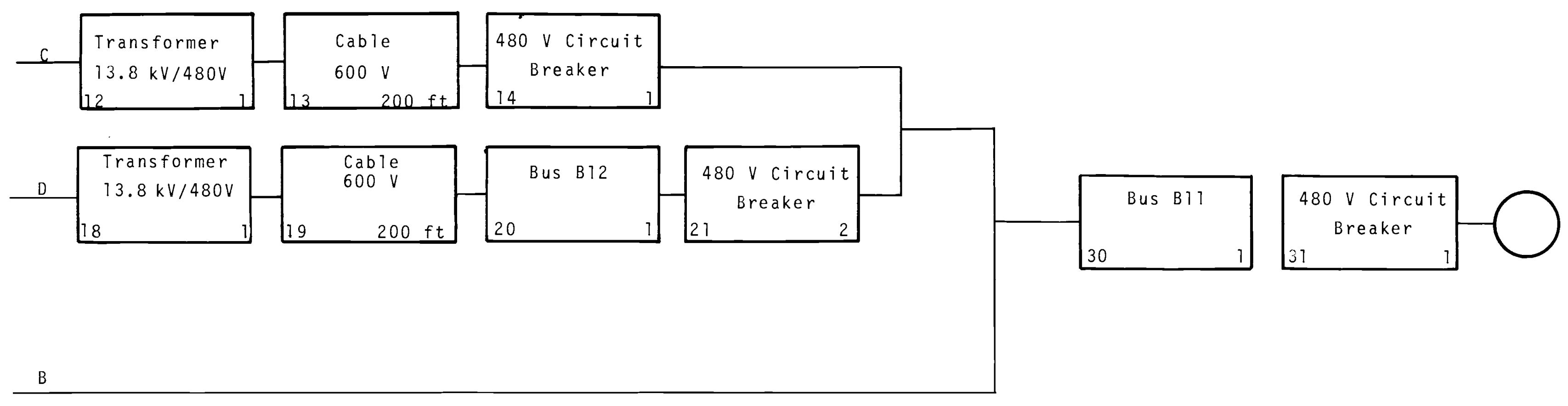




$$
\begin{aligned}
& A_{E B}=1-\left\{1-\left[1-\left(\lambda_{1}{ }^{\tau} 1+\lambda_{2}{ }^{\tau} 2+\lambda_{3}{ }^{\tau} 3+\lambda_{4}{ }^{\tau}\right)^{2}\right]\left[1-\left(\lambda_{9}{ }^{\tau} 9+\lambda_{10}{ }^{\tau} 10+\lambda_{11}{ }^{\tau} 11\right.\right.\right. \\
& \left.+\lambda_{12}{ }^{\tau} 12+\lambda_{13}{ }^{\tau} 13+\lambda_{14}{ }^{\tau} 14\right)\left(\lambda_{15}{ }^{\tau} 15+\lambda_{16}{ }^{\tau} 16+\lambda_{17}{ }^{\tau} 17+\lambda_{18}{ }^{\tau} 18+\lambda_{19}{ }^{\tau} 19\right. \\
& \left.\left.\left.+\lambda_{20}{ }^{\tau} 20+\lambda_{21}{ }^{\tau} 21\right)\right]\right\}\left(\lambda_{22}{ }^{\tau} 22+\lambda_{23}{ }^{\tau} 23+\lambda_{24}{ }{ }_{24}+\lambda_{25}{ }^{\tau} 25\right) \\
& \left(\lambda_{26}{ }^{\tau} 26+\lambda_{27}{ }^{\tau} 27+\lambda_{28}{ }^{\tau} 28+\lambda_{29}{ }^{\tau} 29\right) \\
& \frac{1}{\mathcal{O}_{\mathrm{EB}}}=\left(\lambda_{22}{ }^{\tau} 22+\lambda_{23}{ }^{\tau} 23+\lambda_{24}{ }^{\tau} 24+\lambda_{25}{ }^{\tau} 25\right)\left(\lambda_{26}{ }^{\tau} 26+\lambda_{27}{ }^{\tau} 27+\lambda_{28}{ }^{\tau} 28+\lambda_{29}{ }^{\tau} 29\right) \\
& \left\{\left[1-\left[1-\left(\lambda_{1}{ }^{\tau} 1+\lambda_{2}{ }^{\tau} 2+\lambda_{3}{ }^{\tau} 3+\lambda_{4}{ }^{\tau}\right)^{2}\right]\left[1-\left(\lambda_{9}{ }^{\tau} 9+\lambda_{10}{ }^{\tau} 10+\lambda_{11}{ }^{\tau} 11\right.\right.\right.\right. \\
& \left.+\lambda_{12}{ }^{\tau} 12+\lambda_{13}{ }^{\tau} 13+\lambda_{14}{ }^{\tau} 14\right)\left(\lambda_{15}{ }^{\tau} 15+\lambda_{16}{ }^{\tau} 16+\lambda_{17}{ }^{\tau} 17+\lambda_{18}{ }^{\tau} 18+\lambda_{19}{ }^{\tau} 19\right. \\
& \left.\left.\left.+\lambda_{20}{ }^{\tau} 20+\lambda_{21}{ }^{\tau} 21\right)\right]\right]\left[\frac{\left.{ }_{1}-\left(\lambda_{1}{ }^{\tau} 1+\lambda_{2}{ }^{\tau} 2+\lambda_{3}{ }^{\tau}+\lambda_{4}{ }^{\tau}\right)^{2}\right]\left[1-\left(\lambda_{9}{ }^{\tau} 9\right.\right.}{1-\left[1-\left(\lambda_{1}{ }^{2}{ }+\lambda_{2}{ }^{\tau} 2+\lambda_{3}{ }^{\tau}{ }^{+}{ }^{\lambda}{ }_{4}{ }^{\tau}\right)^{2}\right]\left[1-\left(\lambda_{9}{ }^{\tau} 9\right.\right.}\right.
\end{aligned}
$$

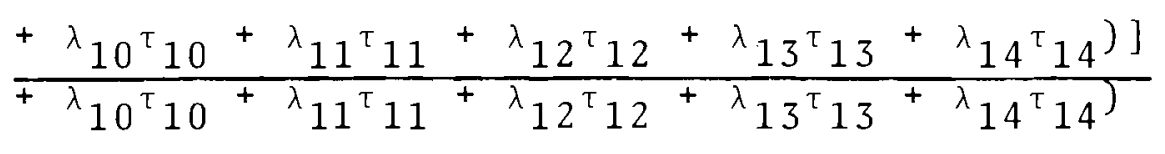

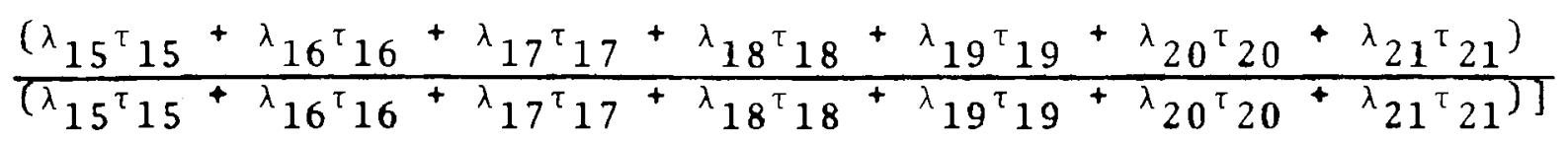

$$
\begin{aligned}
& \text { Math Model for Emergency Bus (Eigure 10) }
\end{aligned}
$$




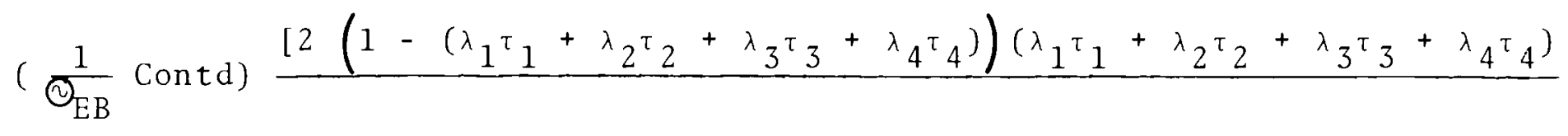

$$
\begin{aligned}
& \left(\lambda_{1}+\lambda_{2}+\lambda_{3}+\lambda_{4}\right)+\left(\lambda_{15^{\tau} 15}+\lambda_{16}{ }^{\tau} 16+\lambda_{17^{\tau} 17}+\lambda_{18}{ }^{\tau} 18+\lambda_{19}{ }^{\tau} 19\right. \\
& \left.+\lambda_{20}{ }^{\tau} 20+\lambda_{21}{ }^{\tau} 21\right)\left(1-\left(\lambda_{9}{ }^{\tau} 9+\lambda_{10}{ }^{\tau} 10+\lambda_{11}{ }^{\tau} 11+\lambda_{12}{ }^{\tau} 12+\lambda_{13}{ }^{\tau} 13\right.\right. \\
& \hline
\end{aligned}
$$$$
\left.\left.+\lambda_{14}{ }^{\tau} 14\right)\right)\left(\lambda_{9}+\lambda_{10}+\lambda_{11}+\lambda_{12}+\lambda_{13}+\lambda_{14}\right)+\left(\lambda_{9}{ }^{\tau}+\lambda_{10}{ }^{\tau} 10\right.
$$

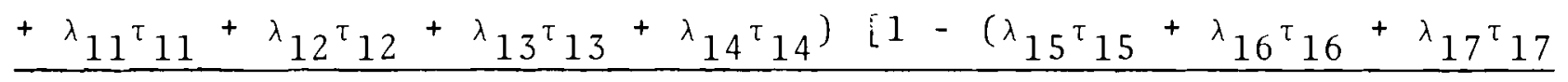$$
\left.+{ }^{\lambda} 18^{\tau} 18+\lambda_{19}{ }^{\tau} 19+\lambda_{20}{ }^{\tau} 20+\lambda_{21}{ }^{\tau} 21\right)\left(\lambda_{15}+\lambda_{16}+\lambda_{17}+\lambda_{18}\right.
$$

$$
\begin{aligned}
& \left.\frac{\left.\left.+\lambda_{19}+\lambda_{20}+\lambda_{21}\right)\right]}{\left[1+\left(\lambda_{22} \tau_{22}+\lambda_{23}\right.\right.}\right] \\
& +\frac{\left[1-\left(\lambda_{22}{ }^{\tau} 22+\lambda_{23^{\tau} 23}+\lambda_{24}{ }^{\tau} 24+\lambda_{25}{ }^{\tau} 25\right)\right]\left(\lambda_{22}+\lambda_{23}+\lambda_{24}+\lambda_{25}\right)}{\left(\lambda_{22}{ }^{\tau} 22+\lambda_{23}{ }^{\tau} 23+\lambda_{24}{ }^{\tau} 24+\lambda_{25}{ }^{\tau} 25\right)} \\
& \left.+\frac{\left[1-\left(\lambda_{26}{ }^{\tau} 26+\lambda_{27}{ }^{\tau} 27+\lambda_{28}{ }^{\tau} 28+\lambda_{29}{ }^{\tau} 29\right)\right]\left(\lambda_{26}+\lambda_{27}+\lambda_{28}+\lambda_{29}\right)}{\left(\lambda_{26}{ }^{\tau} 26+\lambda_{27^{\tau} 27}+\lambda_{28}{ }^{\tau} 28+\lambda_{29}{ }^{\tau} 29\right)}\right\}
\end{aligned}
$$

$$
\tau_{E B}=\left(1-A_{E B}\right)\left(\Theta_{E B}\right)
$$


ANALYSIS OF THE "ZERO TIME OUTAGE" BUSSES

The "zero time outage" (ZTO) busses supply instrumentation and control loads which cannot tolerate momentary power loss. There are two such busses (each with the same arrangement) which have as their normal source the $480 \mathrm{~V}$ ac emergency power bus. In addition, each bus is connected to a synchronous alternator that is floating on the line and will deliver power through flywheel inertia in event of momentary outages. The alternator is also driven by a dc motor and clutch from the $125 \mathrm{~V}$ dc system。 The dc drive will provide alternator power for extended outages.

This arrangement of sources of power and equipment configuration results in a complicated reliability block diagram。The most difficult of analysis is the provision that B11 can supply the $125 \mathrm{~V}$ dc system in event of power failure to $B 17$, but the reverse flow of power, from $B 17$ to Bll is precluded. To facilitate the present analysis, this connection of B11 to supply the $125 \mathrm{~V}$ dc system is omitted. As a consequence, the results of the analysis will be pessimistic because this connection provides an additional path for success。

The reliability block diagram of the ZTO bus is shown in Figure 11 and the results of the analysis are as follows:

For one zTO bus

Availability of powe $r=0.9999999615$

(unavailability $=0.0385 \times 10^{-6}$ )

Mean-time-between-failure $=106,000,000 \mathrm{hr}$

Mean $\approx$ time - to $\sim$ restore $=5.12 \mathrm{hr}$

For any load on the ZTO bus

Availability of power $=0.9999831$

(unavailability $=16.9 \times 10^{\circ}$ )

Mean-time-between-failure $=220,000 \mathrm{hr}$

Mean-time-to restore $=3.93 \mathrm{hr}$ 


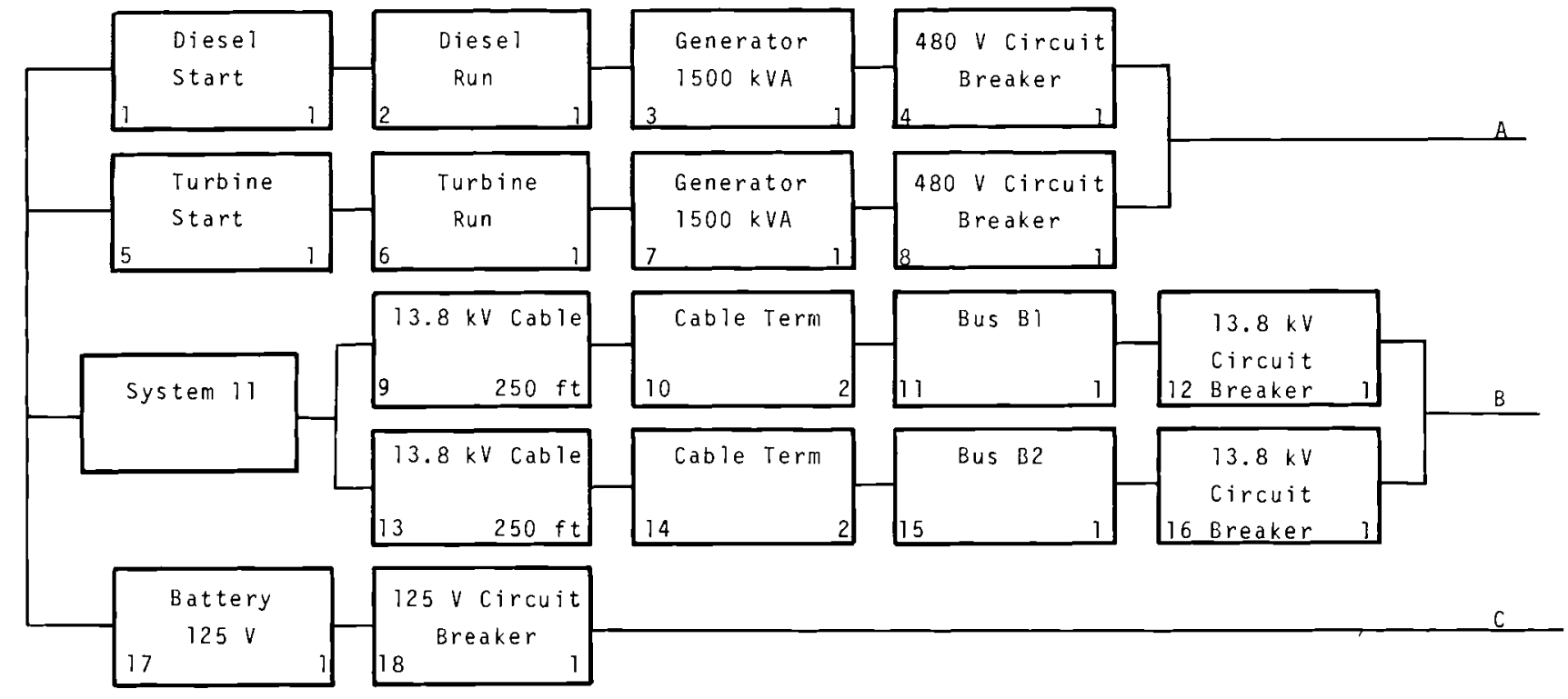

$\infty$
1
1
$\omega$
$\omega$ 


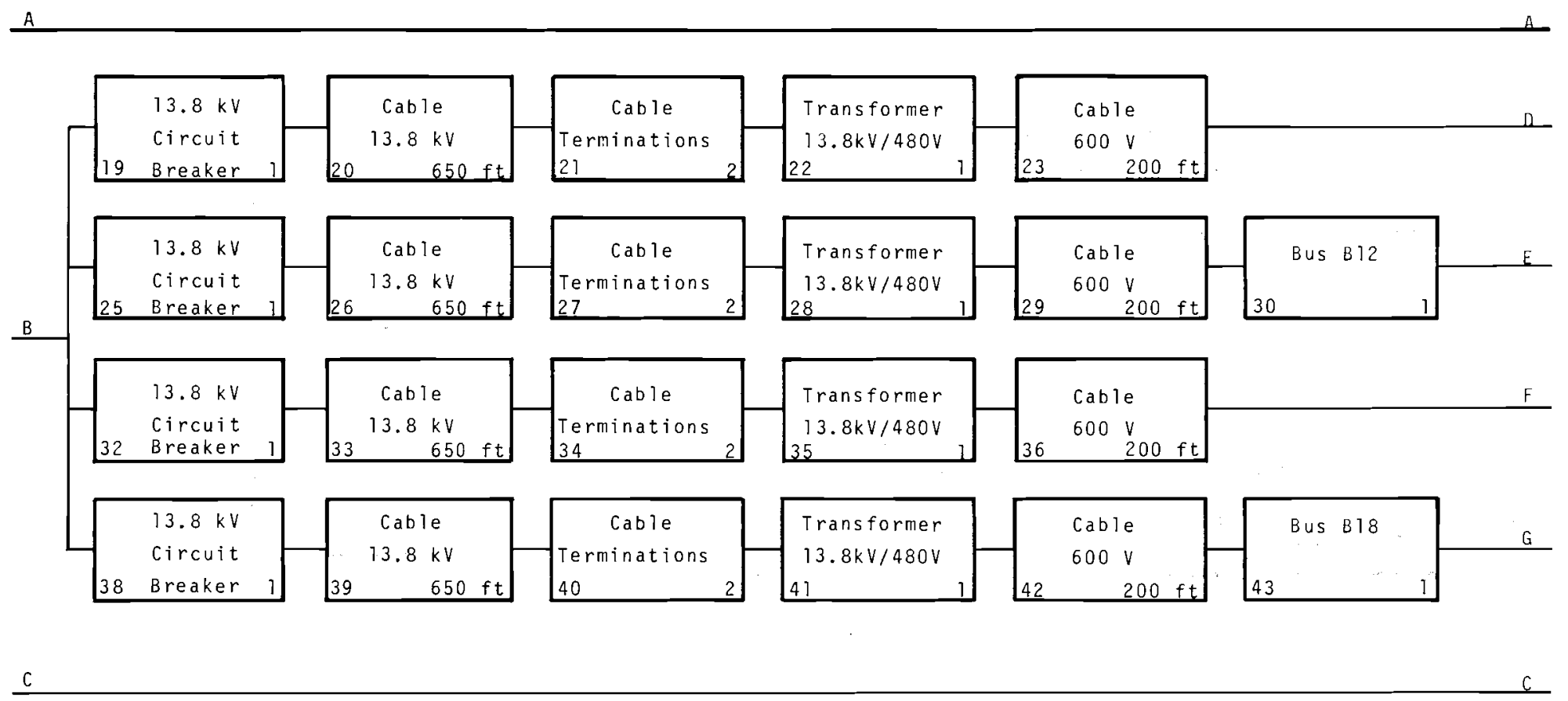




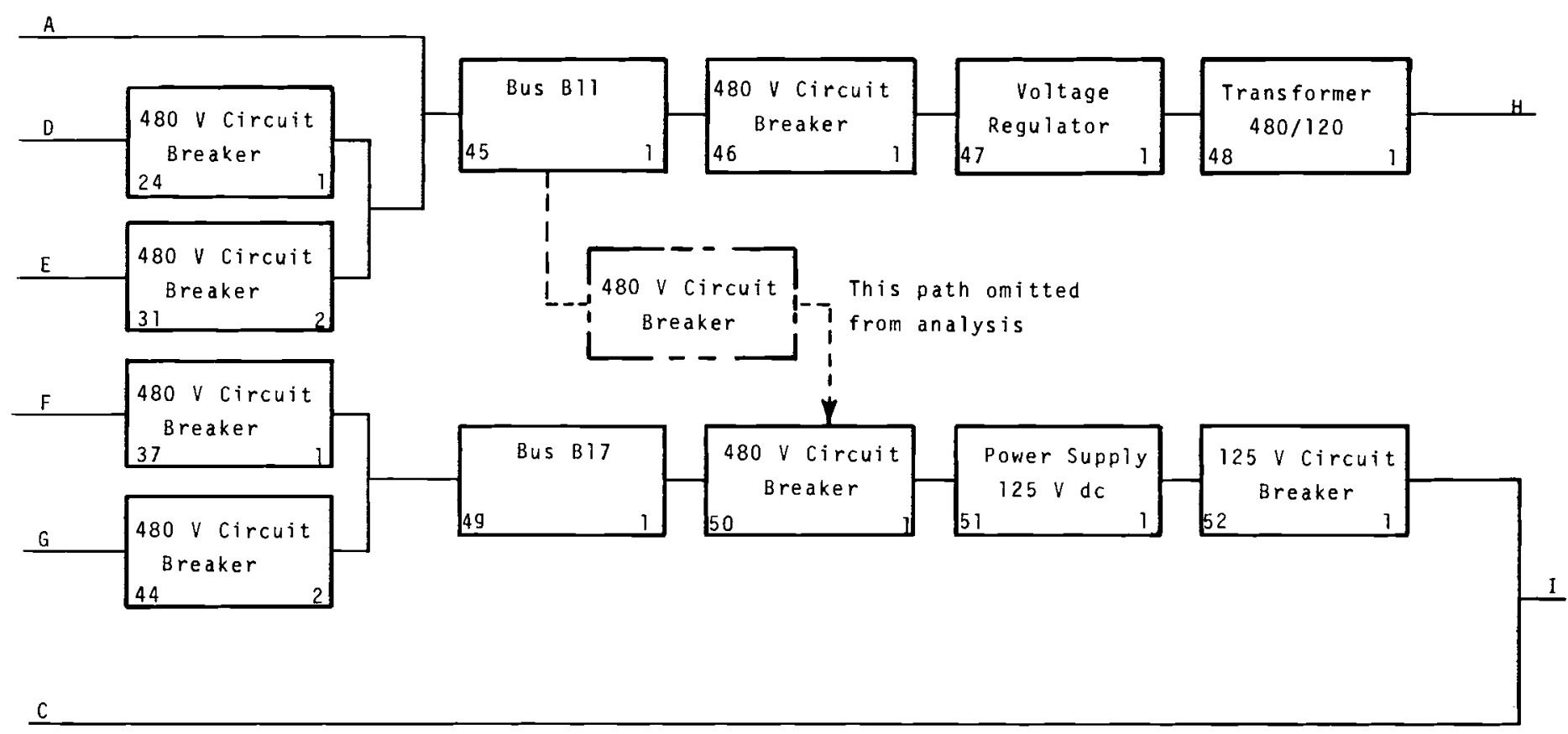




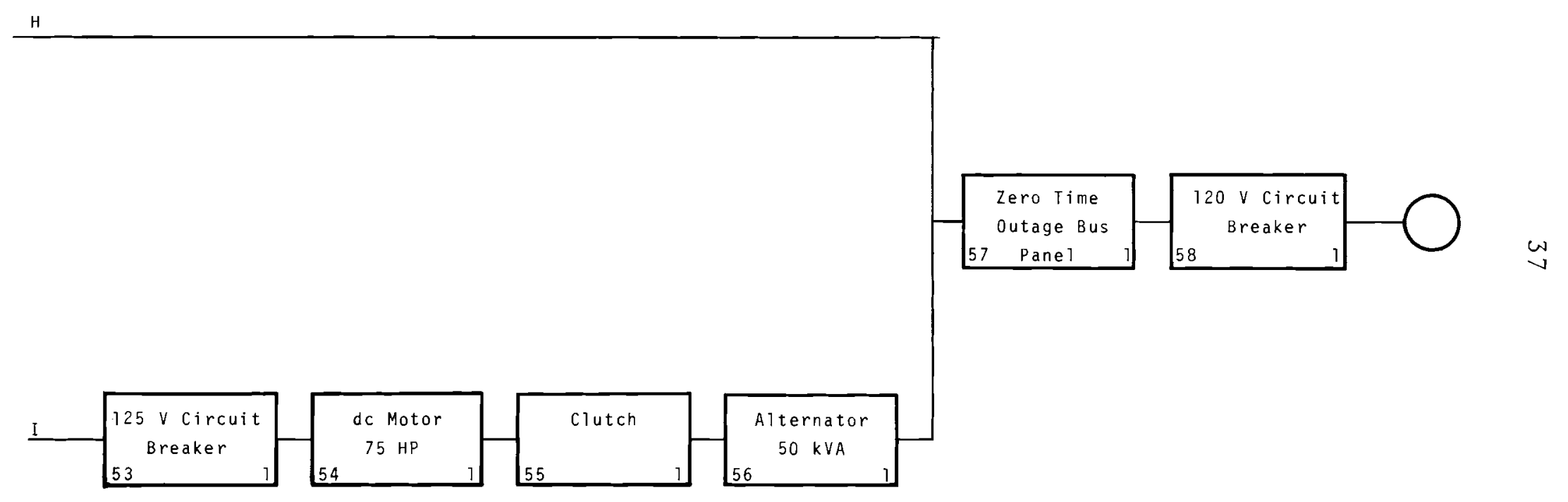

FIGURE 11. (Contd) 


$$
\begin{aligned}
& A_{Z T O}=\left(A_{v} A_{m}+A_{x} A_{k}-A_{v} A_{m} A_{x} A_{k}\right)+A_{D}^{2}\left[\left(A_{c} A_{k}+A_{f} A_{m}\right.\right. \\
& \left.\left.-A_{c} A_{k} A_{f} A_{m}\right)-\left(A_{v} A_{m}+A_{x} A_{k}-A_{v} A_{m} A_{x} A_{k}\right)\right] \\
& \frac{1}{\vartheta_{Z T 0}}=\frac{1-\bar{A}_{D}^{2}}{\frac{\bar{A}_{W} A_{t}}{\vartheta_{t}}+\frac{\bar{A}_{t} A_{W}}{\vartheta_{W}}}+\frac{\bar{A}_{D}^{2}}{\frac{\bar{A}_{y} A_{z}}{\vartheta_{z}}+\frac{\bar{A}_{z} A_{y}}{\partial_{y}}} \\
& +\frac{2 \bar{A}_{d} A_{d}}{\mathcal{O}_{d}}\left(A_{j} A_{k} \bar{A}_{c} \bar{A}_{f}+A_{j} A_{k} \bar{A}_{c} \bar{A}_{m}+A_{q} A_{m} \bar{A}_{c} \bar{A}_{f}+A_{q} A_{m} \bar{A}_{f} \bar{A}_{k}\right) \\
& \tau_{\text {ZTO }}=\frac{\overline{\mathrm{A}}_{\mathrm{ZTO}}}{\mathrm{A}_{\mathrm{ZTO}}} \vartheta_{\mathrm{ZTO}}
\end{aligned}
$$

where

$$
\begin{aligned}
& \overline{\mathrm{A}}_{\mathrm{C}}=1-\mathrm{A}_{\mathrm{C}}=\left(\lambda_{1}{ }^{\tau_{1}}+\lambda_{2}{ }^{\tau}{ }_{2}+\lambda_{3}{ }^{\tau}{ }_{3}+\lambda_{4}{ }_{4}{ }\right)\left(\lambda_{5}{ }^{\tau}{ }_{5}+\lambda_{6}{ }^{\tau} 6+\lambda_{7}{ }_{7}+\lambda_{8}{ }^{\tau_{8}}\right) \\
& \bar{A}_{\mathrm{d}}=1-\mathrm{A}_{\mathrm{d}}=\lambda_{9}{ }^{\tau} 9+\lambda_{10}{ }^{\tau} 10+\lambda_{11}{ }_{11}+\lambda_{12}{ }^{\tau} 12 \\
& \bar{A}_{f}=1-A_{f}=\lambda_{17^{\tau}} 17+\lambda_{18}{ }^{\tau} 18 \\
& \vec{A}_{j}=1-A_{j}=\left(\lambda_{19}{ }^{\tau} 19+\lambda_{20}{ }^{\tau} 20+\lambda_{21}{ }^{\tau} 21+\lambda_{22}{ }^{\tau} 22+\lambda_{23}{ }^{\tau} 23\right. \\
& \left.+\lambda_{24}{ }^{\tau} 24\right)\left(\lambda_{25}{ }^{\tau} 25+\lambda_{26}{ }^{\tau} 26+\lambda_{27^{\tau}}{ }{ }_{27}+\lambda_{28}{ }^{\tau} 28\right. \\
& \left.+\lambda_{29}{ }^{\tau} 29+\lambda_{30}{ }^{\tau} 30+\lambda_{31}{ }^{\tau} 31\right) \\
& \bar{A}_{k}=1-A_{k}=\lambda_{45}{ }^{\tau} 45+\lambda_{46}{ }^{\tau} 46+\lambda_{47^{\tau}}{ }_{47}+\lambda_{48}{ }^{\tau} 48 \\
& \bar{A}_{m}=1-A_{m}=\lambda_{53}{ }^{\tau} 53+\lambda_{54}{ }^{\tau} 54+\lambda_{55^{\tau} 55}+\lambda_{56}{ }^{\tau} 56 \\
& \bar{A}_{q}=1-A_{q}=1-A_{j}\left[1-\left(\lambda_{49^{\tau} 49}+\lambda_{50}{ }^{\tau} 50+\lambda_{51}{ }^{\tau} 51+\lambda_{52}{ }^{\tau} 52\right)\right] \\
& \bar{A}_{t}=1-A_{r}=1-A_{m}\left(1-\bar{A}_{q} \bar{A}_{f}\right)
\end{aligned}
$$$$
\text { Math Model for ZTO Bus (Figure 11) }
$$ 


$$
\begin{aligned}
& \bar{A}_{v}=1-A_{v}=\bar{A}_{q} \bar{A}_{f} \\
& \bar{A}_{W}=1-A_{W}=1-A_{k}\left(1-\bar{A}_{C} \bar{A}_{j}\right) \\
& \bar{A}_{x}=1-A_{x}=\bar{A}_{C} \bar{A}_{j} \\
& \bar{A}_{y}=1-A_{y}=1-A_{f} A_{m} \\
& \bar{A}_{z}=1-A_{z}=1-A_{C} A_{k} \\
& \frac{1}{\vartheta_{\mathrm{d}}}=\lambda_{\mathrm{d}}=\lambda_{9}+\lambda_{10}+\lambda_{11}+\lambda_{12} \\
& \frac{1}{\mho_{t}}=\lambda_{t}=\left(\lambda_{53}+\lambda_{54}+\lambda_{55}+\lambda_{56}\right)\left(\bar{A}_{v} \frac{{ }^{\tau} q+{ }^{\tau} f}{{ }^{\tau} q^{\top} f}\right) \\
& \tau_{f}=\frac{\lambda_{17} \tau_{17}+\lambda_{18}{ }^{\tau} 18}{\lambda_{17}+\lambda_{18}} \\
& \tau_{q}=\bar{A}_{q} Q_{q} \\
& \frac{1}{\vartheta_{\mathrm{q}}}=\left(\lambda_{49}+\lambda_{50}+\lambda_{51}+\lambda_{52}\right)+\bar{A}_{j}\left(\frac{\tau_{g}+\tau_{h}}{\tau_{g}{ }^{\tau} h}\right) \\
& \tau_{g}=\frac{\lambda_{19} \tau_{19}+\lambda_{20} \tau_{20}+\lambda_{21}{ }^{\tau} 21+\lambda_{22}{ }^{\tau} 22+\lambda_{23}{ }_{23}+\lambda_{24}{ }_{22}}{\lambda_{19}+\lambda_{20}+\lambda_{21}+\lambda_{22}+\lambda_{23}+\lambda_{24}} \\
& \tau_{h}=\frac{\lambda_{25} \tau_{25}+\lambda_{26} \tau_{26}+\lambda_{27} \tau_{27}+\lambda_{28} \tau_{28}+\lambda_{29} \tau_{29}+\lambda_{30} \tau_{30}+\lambda_{31} \tau_{31}}{\lambda_{25}+\lambda_{26}+\lambda_{27}+\lambda_{28}+\lambda_{29}+\lambda_{30}+\lambda_{31}} \\
& \frac{1}{\vartheta_{W}}=\left(\lambda_{45}+\lambda_{46}+\lambda_{47}+\lambda_{48}\right)+\bar{A}_{c} \bar{A}_{j}\left(\frac{\tau_{c}+\tau_{j}}{\tau_{c}{ }^{\tau} j}\right) \\
& \tau_{c}=\frac{{ }^{\tau} a{ }^{\tau} b}{\tau_{a}+{ } \tau_{b}} \\
& \tau_{\mathbf{a}}=\frac{\lambda_{1} \tau_{1}+\lambda_{2} \tau_{2}+\lambda_{3} \tau_{3}+\lambda_{4} \tau_{4}}{\lambda_{1}+\lambda_{2}+\lambda_{3}+\lambda_{4}}
\end{aligned}
$$

Math Model for 2 TO (Contd)(Figure 11) 


$$
\begin{aligned}
& \tau_{b}=\frac{\lambda_{5}{ }^{\tau} 5+\lambda_{6}{ }^{\tau} 6+\lambda_{7}{ }^{\tau} 7+\lambda_{8}{ }^{\tau} 8}{\lambda_{5}+\lambda_{6}+\lambda_{7}+\lambda_{8}} \\
& \tau_{j}=\frac{{ }^{\tau} g{ }^{\tau} h}{\tau_{g}+\tau h} \\
& \frac{1}{\vartheta_{z}}=\left(\lambda_{45}+\lambda_{46}+\lambda_{47}+\lambda_{48}\right)+\frac{\bar{A}_{C}}{\tau_{c}} \\
& \frac{1}{\theta_{y}}=\left(\lambda_{17}+\lambda_{18}+\lambda_{53}+\lambda_{54}+\lambda_{55}+\lambda_{56}\right)
\end{aligned}
$$




\section{ANALYSIS OF THE $125 \mathrm{~V}$ de AND $24 \mathrm{~V}$ dc BUSSES}

The dc power systems contain three 125 volt dc busses and two 24 volt dc busses. Each of the busses is supplied from the normal 480 volt system and is automatically switched to the emergency bus if the normal supply fails. A third source for the dc busses is provided by batteries that are paralleled with the busses and are kept in the charged state by the normal power and a dc power supply. The load on the dc systems include critical instruments, emergency lights, and controls.

The sources of power and equipment arrangements are the same for the $125 \mathrm{~V}$ dc and the $24 \mathrm{~V}$ dc systems. The only difference occurs in the dc power supply and the battery. It is possible to use a lower voltage circuit breaker for the 24 volt dc system but the effect on the reliability analysis is insignificant。

The reliability block diagram for the 125 volt dc system is shown in Figure 12. The diagram is the same for the 24 volt dc system with the 125 volt equipment replaced by 24 volt units. The results of the analysis are as follows: For the 125 volt dc bus

$$
\begin{aligned}
& \text { Availability of power }=0.999999966 \\
& \text { (unavailability }=0.034 \times 10^{\circ} \text { ) } \\
& \text { Mean-time-between-failure }=54,000,000 \mathrm{hr} \\
& \text { Mean-time-to-restore }=1.83 \mathrm{hr} \\
& \text { For any load on the } 125 \text { volt bus } \\
& \text { Availability of power }=0.99999797 \\
& \text { (unavailability }=2.03 \times 10^{6} \text { ) } \\
& \text { Mean-time-between-failure }=495,000 \mathrm{hr} \\
& \text { Mean-time-to-restore }=1 \mathrm{hr}
\end{aligned}
$$




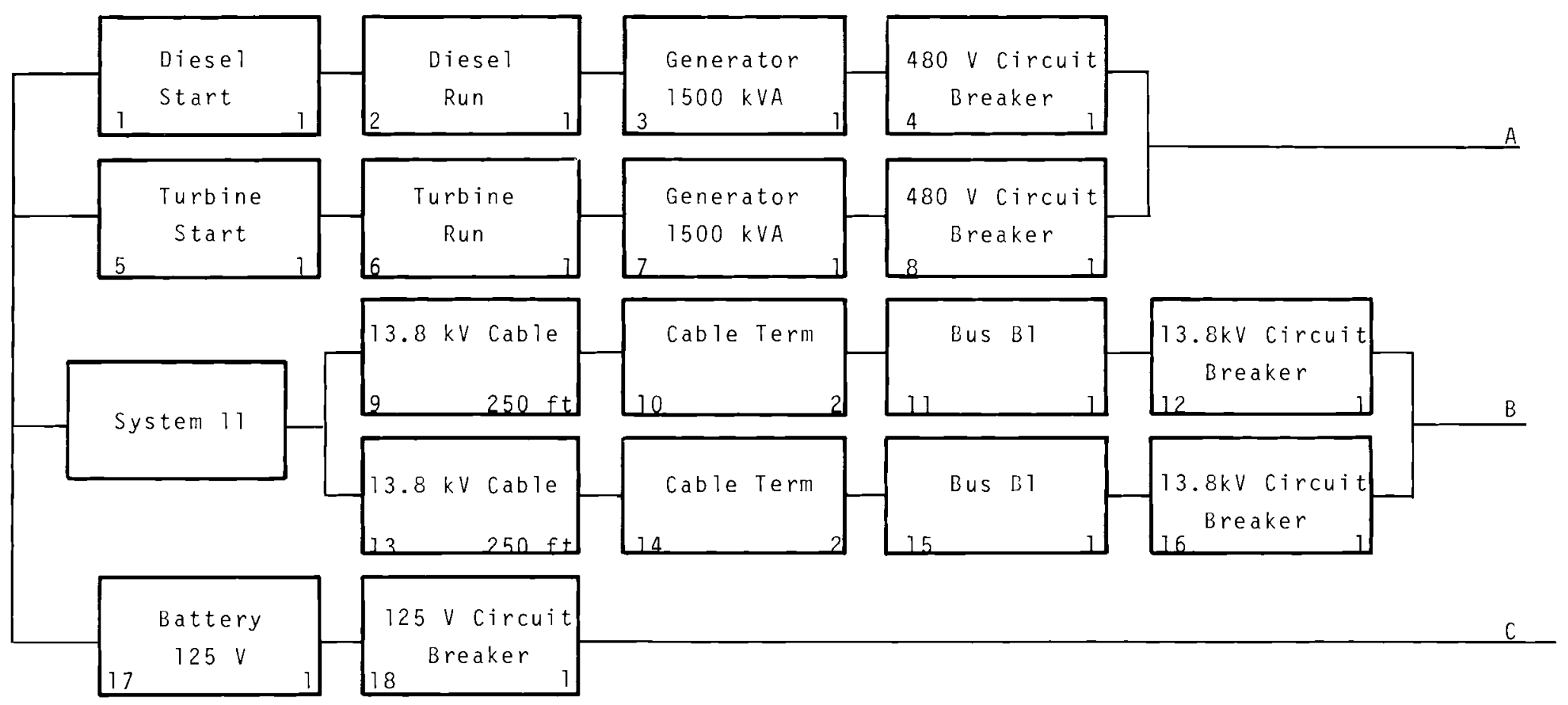

FIGURE 12. Reliability Block Diagram 125 Volt Direct Current System 


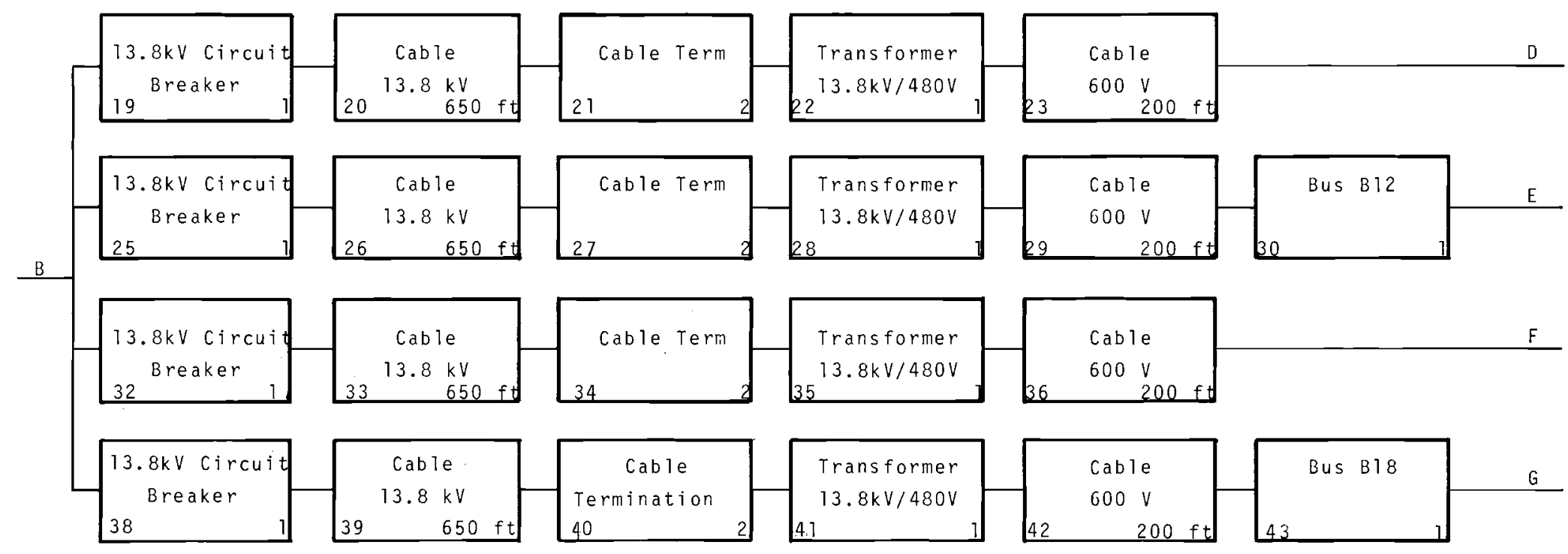




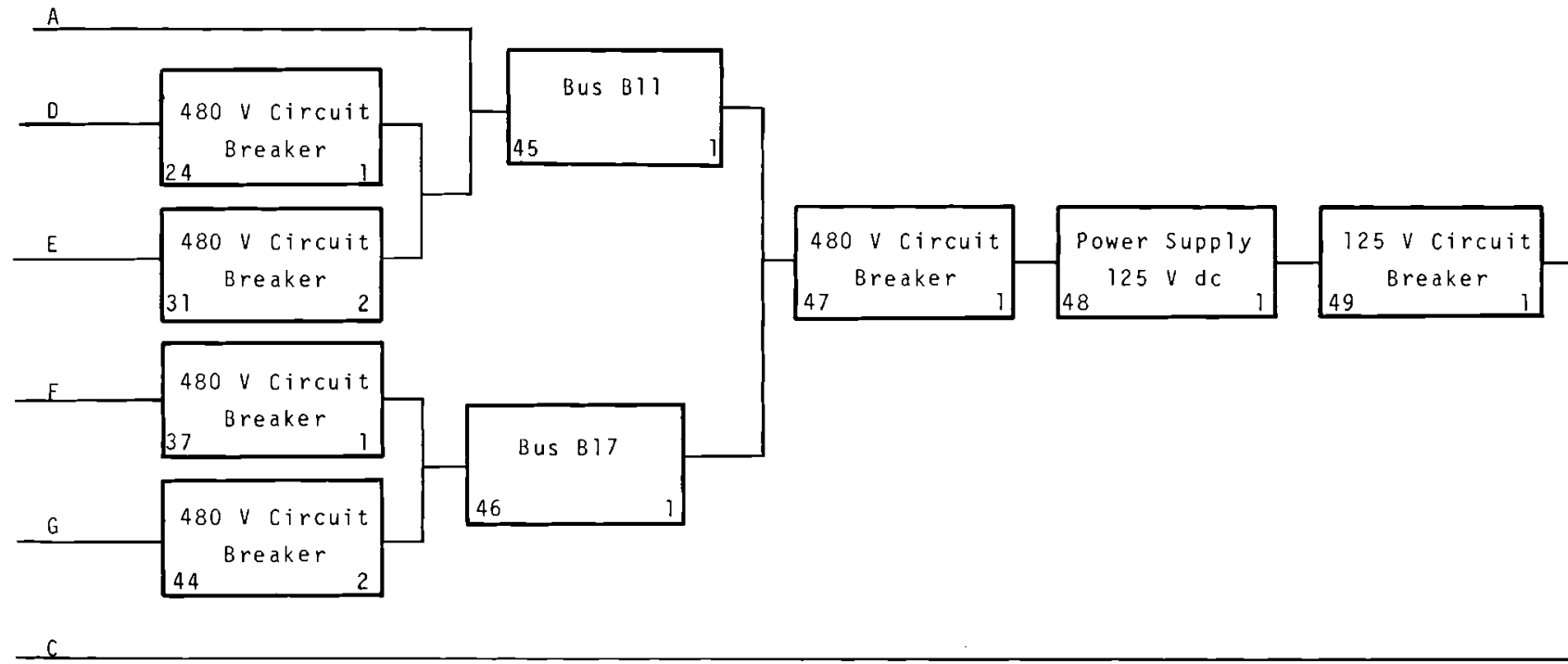




$$
\begin{aligned}
A_{D C}= & 1-\bar{A}_{f}\left\{1-A_{k}\left[\left(1-\bar{A}_{e}\right)\left(1-\bar{A}_{q} \bar{A}_{w}\right)+\bar{A}_{e} A_{c} A_{45}\right]\right\} \\
\frac{1}{\bar{O}_{D C}}= & \bar{A}_{f}\left\{1-A_{k}\left[\left(1-\bar{A}_{e}\right)\left(1-\bar{A}_{q} \bar{A}_{w}\right)+\bar{A}_{e} A_{c} A_{45}\right]\right\}\left\{\frac{A_{f} \lambda_{f}}{\bar{A}_{f}}\right. \\
& +\frac{A_{k}\left(A_{e} A_{s}+\bar{A}_{e} A_{o}\right)\left[\lambda_{k}+A_{e}\left(\bar{A}_{W} A_{q} \lambda_{q}+\bar{A}_{q} A_{W} \lambda_{w}\right)\right.}{1-A_{k}\left(A_{e} A_{s}+\bar{A}_{e} A_{o}\right)} \\
& +\frac{\left.\bar{A}_{e}\left(\lambda_{C}+\lambda_{45}\right)+\lambda_{e}\left(A_{j} A_{45} \bar{A}_{c}+A_{q} \bar{A}_{c}+A_{q} \bar{A}_{45}\right)\right]}{\tau_{D C}=} \bar{A}_{D C} \otimes_{D C}
\end{aligned}
$$

where

$$
\begin{aligned}
& \bar{A}_{c}=1-A_{c}=\left(\lambda_{1} \tau_{1}+\lambda_{2}{ }^{\tau} 2+\lambda_{3}{ }{ }_{3}+\lambda_{4} \tau_{4}\right)\left(\lambda_{5}{ }^{\tau} 5+\lambda_{6}{ }^{\tau} 6\right. \\
& +\lambda_{7} \tau_{7}+\lambda_{8}{ }^{\tau}{ }_{8} \\
& \overline{\mathrm{A}}_{\mathrm{e}}=1-\mathrm{A}_{\mathrm{e}}=\left(\lambda_{9} \tau_{9}+\lambda_{10} \tau_{10}+\lambda_{11}{ }^{\tau} 11+\lambda_{12}{ }^{\tau} 12\right)^{2} \\
& \bar{A}_{f}=1-A_{f}=\lambda_{17} \tau_{17}+\lambda_{18}{ }^{\tau} 18 \\
& \overline{\mathrm{A}}_{\mathrm{k}}=1-\mathrm{A}_{\mathrm{k}}=\lambda_{47^{\tau}}{ }_{47}+\lambda_{48}{ }^{\tau} 48+\lambda_{49}{ }^{\tau} 49 \\
& \bar{A}_{j}=1-A_{j}=\left(\lambda_{19}{ }^{\tau} 19+\lambda_{20}{ }^{\tau} 20+\lambda_{21}{ }^{\tau} 21+\lambda_{22}{ }^{\tau} 22+\lambda_{23}{ }^{\tau} 23\right. \\
& \left.+\lambda_{24}{ }^{\tau} 24\right)\left(\lambda_{25}{ }^{\tau} 25+\lambda_{26}{ }^{\tau} 26+\lambda_{27}{ }^{\tau} 27+\lambda_{28}{ }^{\tau} 28\right. \\
& \left.+\lambda_{29}{ }^{\tau} 29+\lambda_{30}{ }^{\tau} 30+\lambda_{31}{ }^{\tau} 31\right)
\end{aligned}
$$

Math Model for 125 Volt Direct Current (Eigure 12) 


$$
\begin{aligned}
& \bar{A}_{0}=1-A_{0}=1-A_{C}\left(1-\lambda_{45}{ }^{\top} 45\right) \\
& \bar{A}_{q}=1-A_{q}=1-A_{j}\left(1-\lambda_{46}{ }^{\top} 46\right) \\
& \bar{A}_{S}=1-A_{S}=\bar{A}_{q}\left[1-\lambda_{45}{ }^{\top} 45\left(1-\bar{A}_{C} \bar{A}_{j}\right)\right] \\
& \bar{A}_{W}=1-A_{W}=1-\lambda_{45^{\tau} 45}\left(1-\bar{A}_{c} \bar{A}_{j}\right) \\
& \bar{A}_{45}=1-A_{45}=\lambda_{45^{\top}}{ }_{45} \\
& \lambda_{\mathrm{f}} \dot{\dot{x}} \lambda_{17}+\lambda_{18} \\
& \lambda_{\mathrm{k}}=\lambda_{47}+\lambda_{48}+\lambda_{49} \\
& \lambda_{\mathrm{q}}=\left(\lambda_{19}{ }^{\tau} 19+\lambda_{20}{ }^{\tau} 20+\lambda_{21}{ }^{\tau} 21+\lambda_{22}{ }^{\tau} 22+\lambda_{23}{ }^{\tau} 23+\lambda_{24}{ }^{\tau} 24\right) \\
& \left(\lambda_{25}+\lambda_{26}+\lambda_{27}+\lambda_{28}+\lambda_{29}+\lambda_{30}+\lambda_{31}\right) \\
& {\left[1-\left(\lambda_{25}{ }^{\tau} 25+\lambda_{26}{ }^{\tau} 26+\lambda_{27}{ }^{\tau} 27+\lambda_{28}{ }^{\tau} 28+\lambda_{29}{ }^{\tau} 29\right.\right.} \\
& \left.\left.+\lambda_{30}{ }{ }_{30}+\lambda_{31}{ }^{\tau} 31\right)\right]+\left(\lambda_{25}{ }^{\tau} 25+\lambda_{26}{ }^{\tau} 26+\lambda_{27}{ }^{\tau} 27\right. \\
& \left.+\lambda_{28}{ }^{\tau} 28+\lambda_{29}{ }^{\tau} 29+\lambda_{30}{ }^{\tau} 30+\lambda_{31}{ }^{\tau} 31\right)\left(\lambda_{19}+\lambda_{20}\right. \\
& \left.+\lambda_{21}+\lambda_{22}+\lambda_{23}+\lambda_{24}\right)\left[1-\left(\lambda_{19}{ }^{\tau} 19+\lambda_{20}{ }^{\tau} 20\right.\right. \\
& \left.+\lambda_{21}{ }^{\tau} 21+\lambda_{22}{ }^{\tau} 22+\lambda_{23}{ }^{\tau} 23+\lambda_{24}{ }^{\tau} 24\right]+\lambda_{46}
\end{aligned}
$$

Math Model for 125 Volt Direct Current System (Contd)(Figure12) 


$$
\begin{aligned}
& \lambda_{w}=\bar{A}_{j} \bar{A}_{c}\left(\frac{{ }^{\tau} a^{\tau} b}{\tau_{a}+{ }^{\tau} b}+\frac{{ }^{\tau} g^{\tau} h}{\tau_{g}+{ }^{\top} h}\right)+\lambda_{45} \\
& \tau_{a}=\frac{\lambda_{1} \tau_{1}+\lambda_{2} \tau_{2}+\lambda_{3} \tau_{3}+\lambda_{4} \tau_{4}}{\lambda_{1}+\lambda_{2}+\lambda_{3}+\lambda_{4}} \\
& \tau_{b}=\frac{\lambda_{5} \tau_{5}+\lambda_{6}{ }_{6}+\lambda_{7}{ }^{\tau}+\lambda_{8}{ }^{\tau} 8}{\lambda_{5}+\lambda_{6}+\lambda_{7}+\lambda_{8}} \\
& \tau_{g}=\frac{\lambda_{19} \tau_{19}+\lambda_{20} \tau_{20}+\lambda_{21} \tau_{21}+\lambda_{22} \tau_{22}+\lambda_{23} \tau_{23}+\lambda_{24} \tau_{24}}{\lambda_{19}+\lambda_{20}+\lambda_{21}+\lambda_{22}+\lambda_{23}+\lambda_{24}} \\
& \tau_{h}=\frac{\lambda_{25}{ }^{\tau} 25+\lambda_{26}{ }^{\tau} 26+\lambda_{27} \tau_{27}+\lambda_{28}{ }^{\tau} 28+\lambda_{29}{ }^{\tau} 29+\lambda_{30}{ }_{30}+\lambda_{31} \tau_{31}}{\lambda_{25}+\lambda_{26}+\lambda_{27}+\lambda_{28}+\lambda_{29}+\lambda_{30}+\lambda_{31}} \\
& \lambda_{c}=\bar{A}_{c}\left(\frac{\tau_{a}+\tau_{b}}{\tau_{a} \tau_{b}}\right) \\
& \lambda_{e}=\bar{A}_{e}\left(\frac{2\left(\lambda_{9}+\lambda_{10}+\lambda_{11}+\lambda_{12}\right)}{\lambda_{9}{ }^{\tau} 9+\lambda_{10}{ }^{\tau} 10+\lambda_{11}{ }^{\tau} 11+\lambda_{12}{ }^{\tau} 12}\right)
\end{aligned}
$$

Math Model for 125 Volt Direct Current System (Contd)(Eigure 12) 
For the 24 volt dc bus

Availability of power $=0.999999983$

(unavailability $=0.017 \times 10^{-6}$ )

Mean-time-between-failure $=109,000,000 \mathrm{hr}$

Mean-time-to-restore $=1.85 \mathrm{hr}$

For any 24 volt dc load

Availability of power $=0.99999898$

(unavailability $=2.02 \times 10^{-6}$ )

Mean-time-between-failure $=497,000 \mathrm{hr}$

Mean-time-to-restore $=1 \mathrm{hr}$

\section{ANALYSIS OF THE 120 VOLT ALTERNATE CURRENT BUSSES}

There are two 120 volt ac busses that serve instrumentation and control loads and are associated with the "zero time outage" busses. However, they do not have the alternator source of the ZTO busses and are supplied by the $480 \mathrm{~V}$ ac emergency bus. The reliability diagram (Figure 13) for each of these $120 \mathrm{~V}$ ac busses is a series arrangement of circuit breaker, voltage regulator, and transformer connected to the emergency bus. In effect, this is a connected load of the 480 volt emergency bus with the additional components mentioned above.

$$
\begin{aligned}
& \text { For one } 120 \text { volt bus } \\
& \text { Availability of power }=0.9999558 \\
& \text { (unavailability }=44.2 \times 10^{-6} \text { ) } \\
& \text { Mean-time-between-failure }=100,000 \mathrm{hr} \\
& \text { Mean-time-to-restore }=4.4 \mathrm{hr}
\end{aligned}
$$


Math Model of $120 \mathrm{~V}$ Bus

$$
\begin{aligned}
& \bar{A}_{S}=\lambda_{1} \tau_{1}+\lambda_{2} \tau_{2}+\lambda_{3} \tau_{3}+\lambda_{4}{ }^{\tau} 4 \\
& \bigotimes_{S}=\frac{1}{\lambda_{1}+\lambda_{2}+\lambda_{3}+\lambda_{4}} \\
& \tau_{S}=\frac{\bar{A}_{S} \bigotimes_{S}}{A_{S}}
\end{aligned}
$$

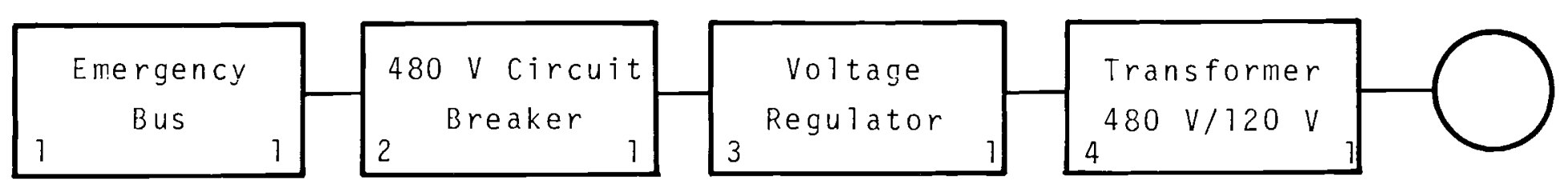

FIGURE 13. Reliability Block Diagram 120 Volt

Instrument and Control Busses 


\section{ANALYSIS OF THE STATION SEPVICE}

Power for the Station Service is utilized at 125 volts dc. The normal supply for the Station Service is redundant circuits each with a circuit breaker, cable, and $13.8 \mathrm{kV} / 480 \mathrm{~V}$ $300 \mathrm{kVA}$ transformer. The $480 \mathrm{~V}$ is then converted to $125 \mathrm{~V} \mathrm{dc}$ by a power supply. An alternative source for the Station Service is a $125 \mathrm{~V}$ battery which is floating on the bus and kept in the charged state by the dc power supply. The load on the station Service includes the operating coils of the $13.8 \mathrm{kV}, 2.4 \mathrm{kV}$, and $480 \mathrm{~V}$ switchgear, interlocks, relays, and substation lighting.

The reliability block diagram for the Station Service is shown in Figure 14, and the results of the analysis are as follows:

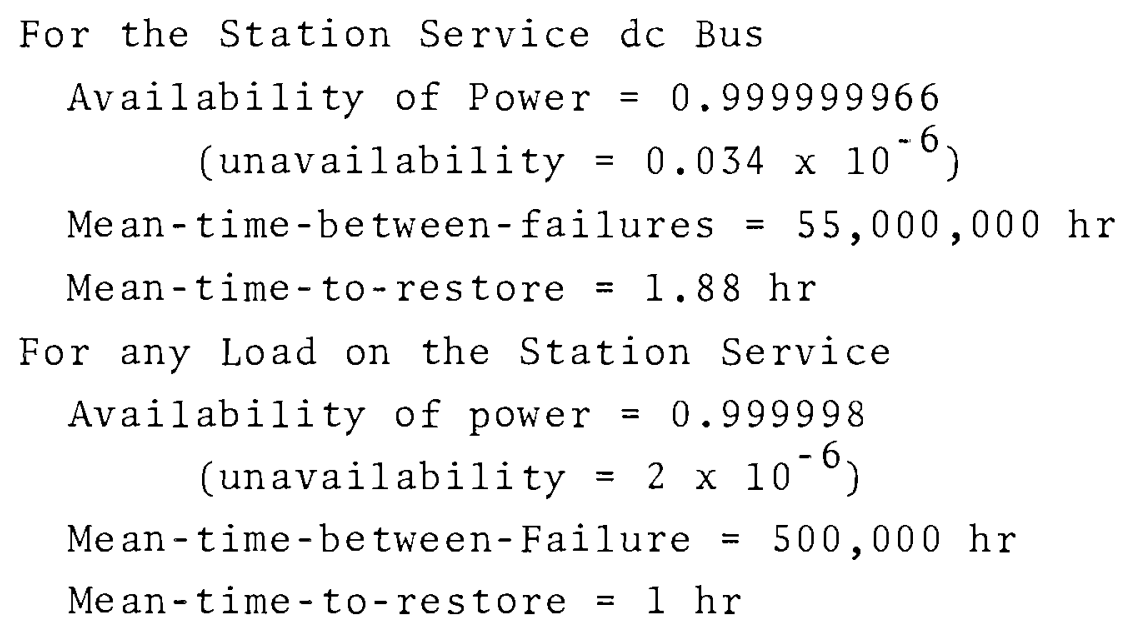



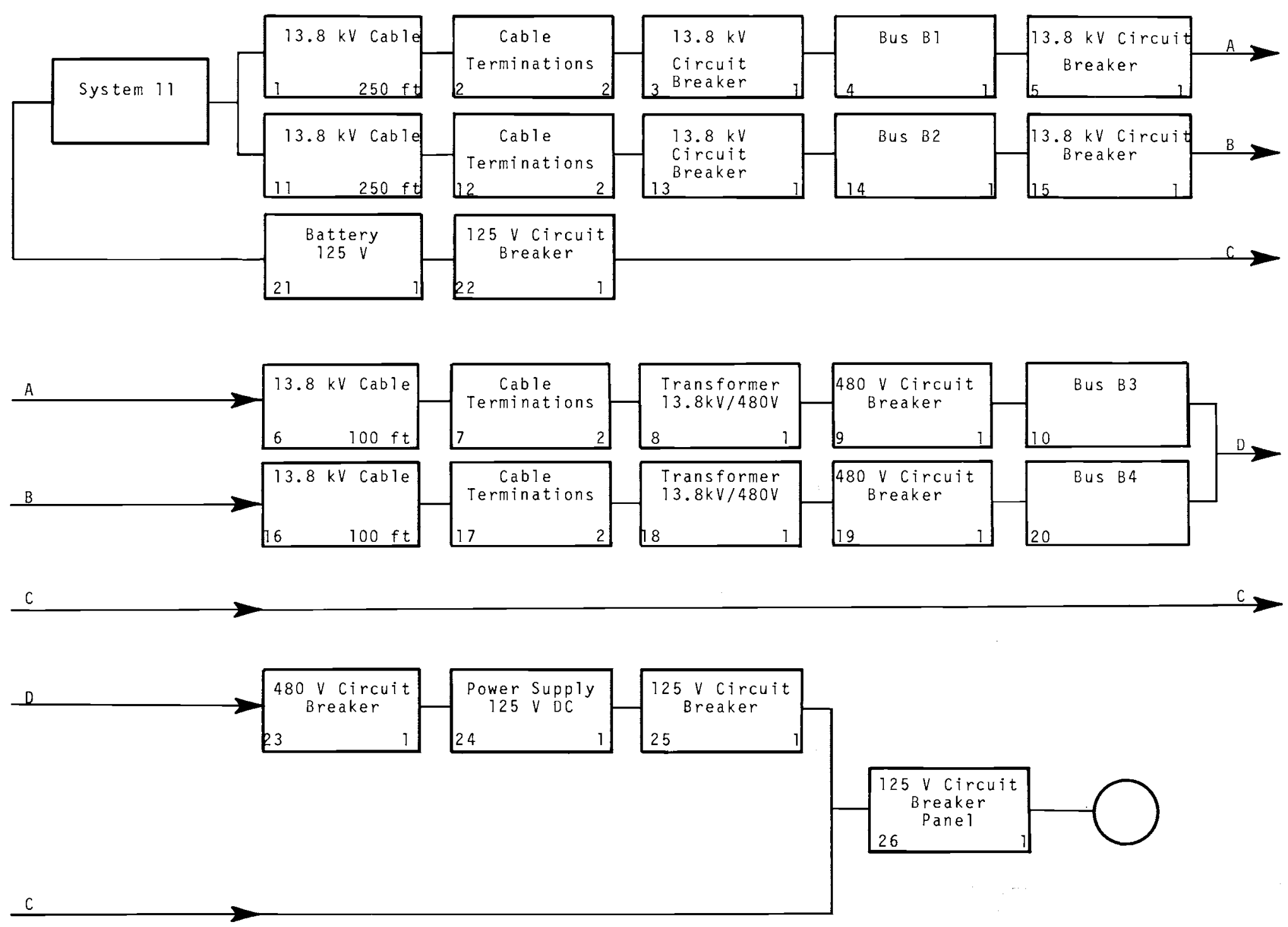

FIGURE 14. Reliability Block Diagram for station Service 


$$
\begin{aligned}
& A_{S}=1-\left\{( \lambda _ { 2 1 } { } ^ { \top } 2 1 + \lambda _ { 2 2 } { } ^ { \tau } 2 2 ) \left[1-\left[1-\left(\lambda_{23}{ }^{\top} 23+\lambda_{24}{ }^{\top} 24\right.\right.\right.\right. \\
& \left.\left.+\lambda_{25}{ }^{\tau} 25\right)\right]\left[1-\left(\lambda_{1}{ }^{\tau}{ }_{1}+\lambda_{2}{ }^{\tau} 2+\lambda_{3}{ }^{\tau} 3+\lambda_{4}{ }^{\tau} 4+\lambda_{5}{ }^{\tau} 5\right.\right.
\end{aligned}
$$

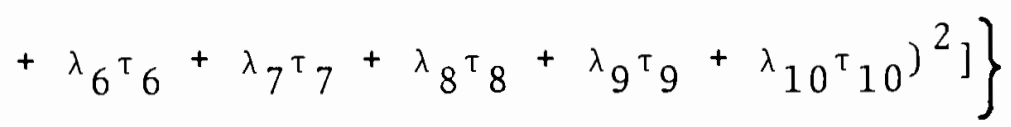

$$
\begin{aligned}
& \frac{1}{\sigma_{\mathrm{S}}}=\left(\lambda_{21}+\lambda_{22}\right)\left\{1-\left[1-\left(\lambda_{23}{ }^{\tau} 23+\lambda_{24}{ }^{\tau} 24+\lambda_{25}{ }^{\tau} 25\right)\right]\right\} \\
& {\left[1-\left(\lambda_{1}{ }^{\tau}{ }_{1}+\lambda_{2}{ }^{\tau} 2+\lambda_{3}{ }^{\tau} 3+\lambda_{4}{ }^{\tau} 4+\lambda_{5}{ }^{\tau} 5+\lambda_{6}{ }^{\tau} 6\right.\right.} \\
& \left.\left.+\lambda_{7}{ }{ }_{7}+\lambda_{8}{ }^{\tau} 8+\lambda_{9}{ }^{\tau} 9+\lambda_{10}{ }^{\tau} 10\right)^{2}\right] \\
& +\left(\lambda_{21} \tau_{21}+\lambda_{22} \tau_{22}\right)\left\{\left(\lambda_{23}+\lambda_{24}+\lambda_{25}\right)+\left[2 \left(\lambda_{1}\right.\right.\right. \\
& \left.+\lambda_{2}+\lambda_{3}+\lambda_{4}+\lambda_{5}+\lambda_{6}+\lambda_{7}+\lambda_{8}+\lambda_{9}+\lambda_{10}\right) \\
& \left(\lambda_{1}{ }^{\tau} 1+\lambda_{2}{ }^{\tau} 2+\lambda_{3}{ }^{\tau} 3+\lambda_{4}{ }^{\tau} 4+\lambda_{5}{ }^{\tau} 5+\lambda_{6}{ }^{\tau} 6+\lambda_{7} \tau_{7}\right. \\
& \left.\left.\left.+\lambda_{8}{ }^{\tau} 8+\lambda_{9} \tau_{9}+\lambda_{10}{ }^{\tau_{10}}\right)\right]\right\} \\
& \tau_{S}=\bar{A}_{S} O_{S}
\end{aligned}
$$

Math Model for Station Service (Figure 14) 


\section{EFFECTS OF BUILDING ELECTRICAL POWER SYSTEM}

FAILURES ON REACTOR AVAILABILITY

The emergency power busses represent the only significant equipment in System 12 that will have an effect on reactor availability. To determine reactor unavailability it is assumed that any failure in either of the two normal sources to the emergency busses will cause the reactor to be shutdown. The expected reactor downtime caused by failures in the emergency busses (per 1000 hours of operation) is:

$$
\sum \lambda_{i} D_{i}(1000)=0.76 \mathrm{hr}
$$

where $D_{i}$ is the component repair time plus the one hour required for the reactor to recover from a shutdown.

It is possible to operate the reactor and the FFTF with a failure in one of the normal sources of power to the emergency busses. However, present plans and procedures require that the reactor be shutdown automatically during such a condition. Any revisions in this procedure or changes in the conceptual configuration of system 12 equipment, will necessitate reevaluation of the above reactor unavailability. 


\section{NOMENCLATURE}
A = Availability of component or system
$\overline{\mathrm{A}}=$ Unavailability of component or system

$$
A=1-\bar{A}
$$
$\lambda=$ Failure rate of component or system
(2) = Mean-time-between-failure of a component or system $\left(0=\frac{1}{\lambda}\right.$ for the exponential distribution
$\tau=$ Mean-time-to-restore a component or system that has failed

MTBF $=$ Mean-time-between-failure

MTTR $=$ Mean-time-to-restore

Legend for Block Diagrams

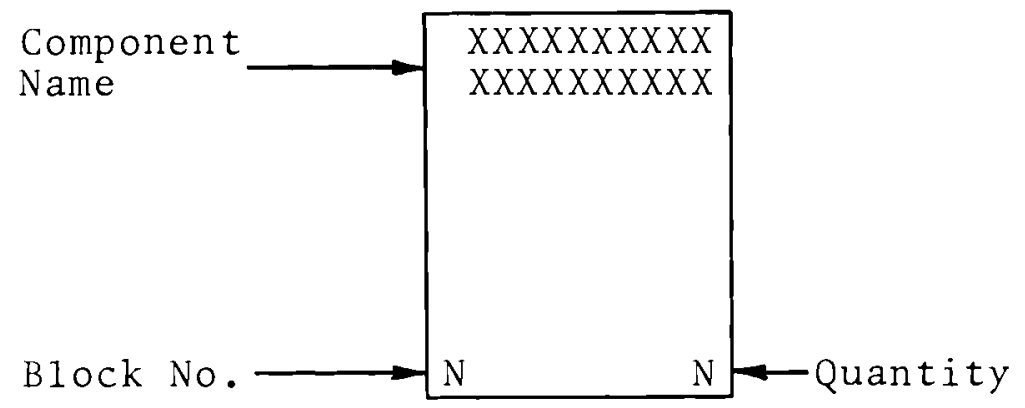




\section{REFERENCES}

1. M. F. Wiitala. Conceptual System Design Description of the Building Electrical Power System, BNWL-500-12. Pacific Northwest Laboratory, Richland, Washington, preliminary release December, 1967.

2. O. B. Monteith. Unpublished Data. Pacific Northwest Laboratory, Richland, Washington, February 1968. (Preziminary Report)

3. Reliability Engineering, Staff of ARINC Research Incorporated, W. H. VonAlven, Editor.

4. W. H. Dickinson. Report on Reliability of Electrical Equipment in Industrial Plants, AIEE Paper 62-61. American Institute of Electrical Engineers, New York, July 1962.

5. S. A. Malzard and V. C. Thomas. "A Method for Calculating Transmission System Reliability," IEEE Paper 31 TP 67-501, July 1967.

6. A. A. Schmudde. "Engine - Generator Sets Meet Strict Reliability Limits," Power. Apriz 1967.

7. G. E. Bratzler and T. R. McMurray. "Generator Set Availability," Power Engineering. November 1967.

8. B. J. Garrick et al. Reliability Analysis of Nuclear Power Plant Protective Systems, HN-190. Holmes and Narver, Incorporated. 
- 


\section{DISTRIBUTION}

No。 of

Copies

U.S.Atomic Energy Commission, Washington

M. Shaw, Director, RDT

Asst Dir for Nuclear Safety

Analysis \& Evaluation Br, RDT:NS

Environmenta1. G Sanitary Engrg

$\mathrm{Br}, \mathrm{RDT}: \mathrm{NS}$

Research \& Development Br, RDT:NS

Asst Dir for Plant Engrg, RDT

Applications \& Facilities Br, RDT:PE

Components $\mathrm{Br}$, RDT:PE

Instrumentation \& Control $\mathrm{Br}, \mathrm{RDT}: \mathrm{PE}$

Liquid Metal Systems Branch, RDT:PE

Asst Dir for Program Analysis, RDT

Asst Dir for Project Mgmt, RDT

Liquid Metals Projects Br, RDT:PM

FFTF Project Manager, RDT:PM (3)

Asst Dir for Reactor Engrg

Control Mechanisms Br, RDT:RE

Core Design Br, RDT:RE (2)

Fue 1 Fabrication $\mathrm{Br}$, RDT:RE

Fue 1 Handling $\mathrm{Br}$, RDT: RE

Reactor Vesse1s Br, RDT:RE

Asst Dir for Reactor Tech

Chemistry \& Chemical Separations $\mathrm{Br}, \mathrm{RDT}: \mathrm{RT}$ (2)

Fuels \& Materials Br, RDT:RT

Reactor Physics Br, RDT:RT

Special Technology Br, RDT:RT

Asst Dir for Engrg Standards

AEC Chicago Patent Group

$\mathrm{G}, \mathrm{H}$ 。 Lee, Chief

R。K。Sharp (Richland)

AEC Idaho Operations Office

C. W. Bills, Director

AEC Richland Operations Office

C. L. Robinson

J. M. Shivley

AEC San Francisco Operations Office

Director, Reactor Division

AEC Division of Technical Information Extension 
No. of Copies

4

AEC Site Representatives-PNL

P.G.Holsted (2)

L。R。 Lucas

A。 D。 Toth

4

2

6

1

1

AEC Site Representatives

Argonne National Laboratory

Atomics International

Atomic Power Development Assoc.

General Electric Co。, Sunnyvale

Argonne National Laboratory

R。A。 Jaross

LMFBR Program Office

Atomics International

Liquid Metal Engrg Center

D。J.Cockeram (5)

R.W. Dickinson (1)

Atomic Power Development Assoc.

Document Librarian

Babcock \&Wilcox Co. (AEC)

S. H。Esleeck

Babcock \& Wilcox Co.

Boiler Division

T.P, Farre11

Sterling Avenue

Barberton, Ohio 44203

1 Combustion Engineering

W. PoStaker, Project Manager

Gulf General Atomic Incorporated (AEC)

General Atomic Division

P.O.Box 608

San Diego, California 92112

D. Coburn 


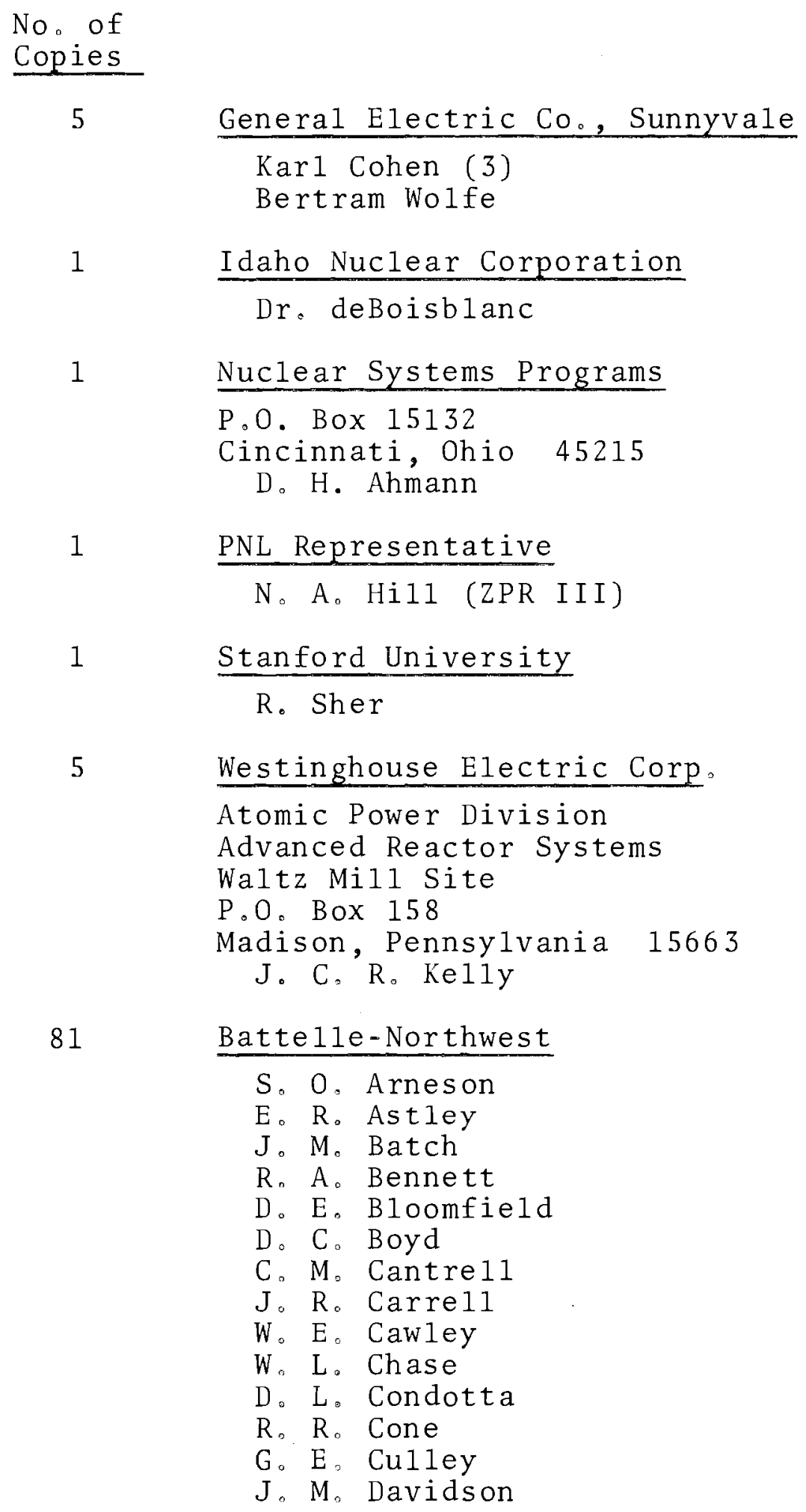




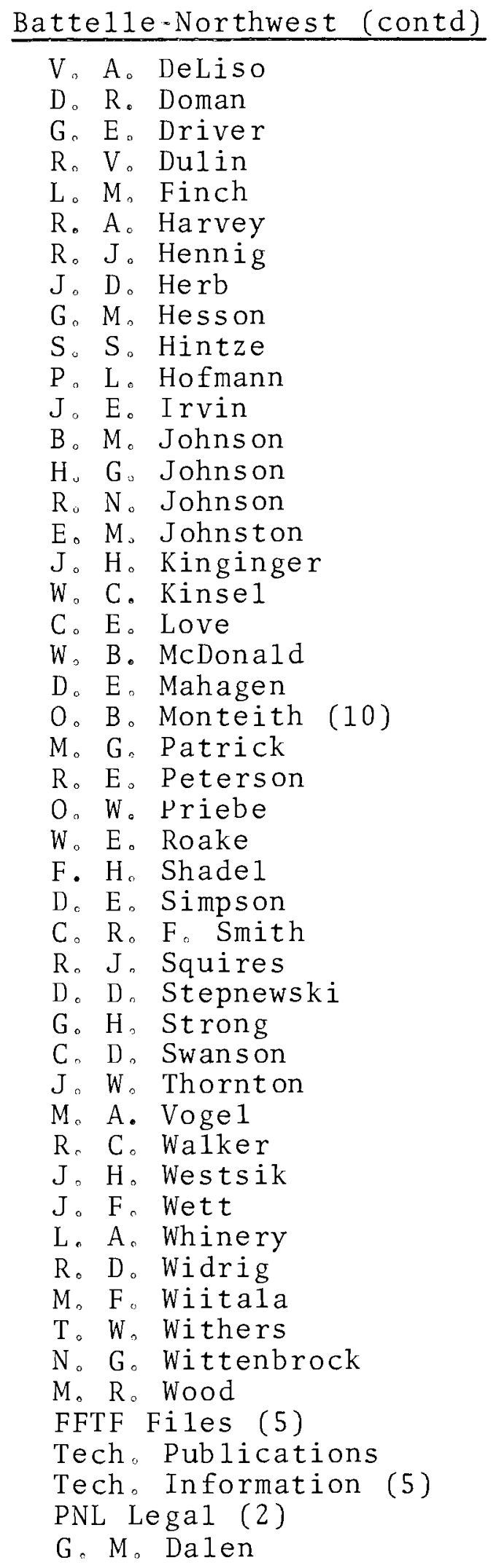

